\title{
Transplantation of Neuronal and Glial Restricted Precursors into Contused Spinal Cord Improves Bladder and Motor Functions, Decreases Thermal Hypersensitivity, and Modifies Intraspinal Circuitry
}

\author{
Takahiko Mitsui, Jed S. Shumsky, Angelo C. Lepore, Marion Murray, and Itzhak Fischer \\ Department of Neurobiology and Anatomy, Drexel University College of Medicine, Philadelphia, Pennsylvania 19129
}

Transplanting neuronal and glial restricted precursors (NRP/GRP) into a midthoracic injury $9 \mathrm{~d}$ after contusion improved bladder and motor function, diminished thermal hypersensitivity, and modified lumbosacral circuitry compared with operated controls (OPcontrols). Histological analysis showed that NRP/GRP survived, filled the lesion site, differentiated into neurons and glia, and migrated selectively. Volume of spinal cord spared was increased in NRP/GRP recipients, suggesting local protection. Bladder areflexia developed in both operated groups, but NRP/GRP recipients exhibited an accelerated recovery, with decreased micturition pressure and fewer episodes of detrusor hyperreflexia. Because noradrenergic receptors proliferate after spinal injury and descending noradrenergic pathways contribute to regulation of bladder control, we examined the effects of administering an $\alpha$-1A-adrenergic antagonist, Tamsulosin, on urodynamics. This improved all cystometric parameters in both operated groups, and micturition pressure in NRP/GRP rats recovered to normal levels. Both operated groups initially showed increased sensitivity to a thermal stimulus applied to the tail; the NRP/GRP rats showed significant improvement over time. NRP/GRP grafts also produced greater recovery of hindlimb function in several tests, although both groups showed persistent and similar deficits in locomotion on a grid.

Because bladder, hindlimb, and tail sensory and motor functions are organized through lumbosacral cord, we examined descending and primary afferent projections at L6 -S1. The density of serotonergic, noradrenergic, and corticotrophin releasing factor-positive fibers increased in the NRP/GRP group compared with OP-controls, suggesting some sparing and/or sprouting of these modulatory pathways. Immunocytochemical staining density of dorsal root axons in the dorsal horn increased in the OP-controls but appeared normal in the NRP/GRP group. Synaptophysin immunoreactivity in the lumbosacral dorsal horn was similar among groups, consistent with restoration of synaptic density in both groups of operated animals but by different pathways. We suggest that local protection provided by $\mathrm{NRP/GRP} \mathrm{resulted} \mathrm{in} \mathrm{increased} \mathrm{sparing/sprouting} \mathrm{of} \mathrm{descending} \mathrm{pathways,} \mathrm{which} \mathrm{prevented} \mathrm{sprouting} \mathrm{by} \mathrm{dorsal} \mathrm{root} \mathrm{axons,} \mathrm{and} \mathrm{that} \mathrm{this}$ modification in lumbosacral circuitry contributes to the recovery of function.

Key words: neural stem cells; neuronal restricted precursors; glial restricted precursors; transplantation; bladder function; Tamsulosin; sensorimotor function; sprouting

\section{Introduction}

Autonomic dysfunction and the neuropathic pain that frequently accompany spinal cord injury (SCI) result from damage to descending pathways and alterations in primary afferent pathways. These disorders are difficult to manage and contribute to poor quality of patient life (Hicken et al., 2001; Widerstrom-Noga et

Received Nov. 12, 2004; revised Sept. 10, 2005; accepted Sept. 11, 2005.

This work was supported by National Institutes of Health Grants NS24707 and NS37515, Spinal Cord Research Foundation Grant 2312-01, The United Spinal Association, and the Uehara Memorial Foundation. We gratefully acknowledge the input that our laboratories provided through discussions and constructive criticism. We thank Nicole M. Amato, Carl Coleman, Andrew M. Diamond, Katina C. Hanford, Carla Tyler-Polsz, and Theresa Connors for their excellent technical assistance. We thank Leopold, Stephen, and Molly for stylistic advice. Yamanouchi Pharma generously provided Tamsulosin.

Correspondence should be addressed to Dr. Marion Murray, Department of Neurobiology and Anatomy, Drexel University College of Medicine, 2900 Queen Lane, Philadelphia, PA 19129. E-mail: mm72@drexel.edu.

DOI:10.1523/JNEUROSCI.2175-05.2005

Copyright $\odot 2005$ Society for Neuroscience $\quad$ 0270-6474/05/259624-13\$15.00/0 al., 2004). SCI produces a dyssynergia between the bladder and urethral sphincter [detrusor-sphincter dyssynergia (DSD)], leading to functional bladder outlet obstruction, identified by urinary retention and increased micturition pressure. Detrusor hyperreflexia (DHR), manifested as phasic bladder contractions during urine storage, results in urinary incontinence and high intravesical pressures, leading to bladder hypertrophy and deterioration of the upper urinary tract. Even modest increases in bladder pressure can elicit episodes of autonomic dysreflexia that can be lifethreatening (Santajuliana et al., 1995). Although there are some treatments for DHR (Pannek et al., 2000; O'Leary et al., 2003), DSD remains difficult to manage without catheterization or surgical interventions. Neuropathic pain develops in the majority of SCI patients, commonly occurs together with autonomic dysfunction (Widerstrom-Noga et al., 2004), can be disabling, and is rarely amenable to treatment. 
Transplantation strategies can promote repair of SCI by providing relays, bridges, inducing selective modifications (regeneration and/or sprouting) of supraspinal and primary afferent pathways, and by neuroprotection of injured neurons or axons. Neuronal and glial restricted precursors (NRP/GRP) survive, differentiate into mature neuronal and glial cells, and migrate selectively when transplanted into adult CNS (Han et al., 2002, 2004; Lepore et al., 2004) and therefore offer the potential for repair and recovery. We transplanted NRP/GRP into a midthoracic contusion injury to determine whether this would (1) reduce DHR (promote storage), (2) ameliorate DSD (permit efficient voiding at low bladder pressures) (Seki et al., 2002; Mitsui et al., 2003) and (3) diminish hypersensitivity to thermal stimuli. Because transplantation strategies are likely to provide only partial recovery, other treatments may still be necessary. Postsynaptic targets of severed descending pathways, particularly monoaminergic pathways, may become more sensitive to transmitters because of receptor upregulation (Roudet et al., 1993; Kim et al., 1999; Y. Hayashi, S. Jacob, J.-M. Nothias, S. McBride, R. Olexa, K. Simansky, M. Murray, and J. S. Shumsky, unpublished observations). The noradrenergic system is implicated in regulation of micturition (Ishizuka et al., 1996; Yoshiyama et al., 2000), and administration of antagonists improve lower urinary tract function in SCI patients (Abrams et al., 2003). We therefore examined the effects of administration of Tamsulosin, an $\alpha-1 \mathrm{~A}$ receptor antagonist, on urodynamics. To determine whether NRP/GRP transplants would also improve sensorimotor function, we also evaluated additional motor functions and response to thermal stimuli.

We analyzed the injury site to determine whether NRP/GRP would survive and differentiate in the environment of a contused spinal cord and whether the graft provided local neuroprotection. The functions of the lower urinary tract are regulated by neural circuits located in the brainstem and their projections through the lateral and ventral funiculi to lumbosacral spinal cord. We also analyzed lumbosacral regions to determine whether these grafts would modify axonal growth from host pathways. Brainstem nuclei project corticotrophin releasing factor (CRF) containing axons (Valentino et al., 1996, 2000), serotonergic (Marson, 1997) and noradrenergic (Vizzard et al., 1995; Marson, 1997) axons to regions in the lumbosacral spinal cord, particularly the spinal parasympathetic nucleus (SPN) and the dorsolateral nucleus (DL) (Nadelhaft and Booth, 1984; Vizzard et al., 1995; Ding et al., 1997; Marson, 1997) that together coordinate the activity of the bladder and urethral sphincter (Pikov and Wrathall, 2001). Some of these modulatory pathways also project to locomotor centers in lumbar spinal cord. Bladder and nociceptive afferents are among the small-caliber axons projecting to the dorsal horn (DH) (Gibson et al., 1984; Jancso and Maggi, 1987; Steers et al., 1991; Chung et al., 1993; Wilson and Kitchener, 1996; Weaver et al., 2001). Descending pathways, including noradrenergic and serotonergic axons, also project to and modulate sensory processing in the $\mathrm{DH}$.

\section{Materials and Methods Animal groups}

Twenty-six female Sprague Dawley rats (225-250 g; Taconic Farms, Germantown, NY) were studied. Twenty rats received a contusion and a transplant of cell culture medium [operated controls (OP-controls); $n=$ 10] or mixed NRP and GRP (NRP/GRP; $n=10)$ at $9 \mathrm{~d}$ after injury. One rat died during surgery, and another was excluded because of incorrect lesion, leaving eight rats in the NRP/GRP group. Six rats were used as unoperated controls. Rats were given access to food and water ad libitum and were kept under a $12 \mathrm{~h}$ light/dark cycle, with lights on at 7:00 A.M. All procedures were approved by the Institutional Animal Care and Use Committee of the Drexel University College of Medicine and conformed to the National Institutes of Health guidelines for the care and use of laboratory animals.

\section{Preparation of NRP and GRP for grafting (Lepore et al., 2004)}

NRPs and GRPs were isolated from embryonic day 13.5 transgenic $\mathrm{Fi}-$ scher 344 rats that express the marker gene human placental alkaline phosphatase (AP). This transgenic animal has been characterized previously (Mujtaba et al., 2002), and the preparation of NRPs and GRPs has been described previously (Han et al., 2002, 2004; Lepore and Fischer, 2004). Briefly, embryos were isolated in DMEM/F-12 (Invitrogen, Carlsbad, CA). Trunk segments were incubated in collagenase type I (10 mg/ $\mathrm{ml}$; Worthington; Lakewood, NJ)/dispase II (20 ng/ml; Roche Diagnostics, Indianapolis, IN)/HBSS (Cellgro, Herndon, VA) solution for $8 \mathrm{~min}$ at room temperature to remove meninges from the cords. Cords were dissociated using a $0.05 \%$ trypsin/EDTA (Invitrogen) solution for $20 \mathrm{~min}$ at $37^{\circ} \mathrm{C}$. Cells were then plated in complete medium [(DMEM/F-12, BSA ( $1 \mathrm{mg} / \mathrm{ml}$; Sigma, St. Louis, MO), B27 (Invitrogen), basic FGF (bFGF) (20 ng/ml; Peprotech, Rocky Hill, NJ), penicillin-streptomycin (100 IU/ $\mathrm{ml}$; Invitrogen), $\mathrm{N} 2(10 \mu \mathrm{l} / \mathrm{ml}$; Invitrogen); bFGF $(10 \mu \mathrm{g} / \mathrm{ml})$ and neurotrophin-3 (NT-3) (10 $\mu \mathrm{g} / \mathrm{ml}$; Peprotech)] on poly-L-lysine-coated (13.3 $\mu \mathrm{g} / \mathrm{ml}$; Sigma) and laminin-coated ( $20 \mu \mathrm{g} / \mathrm{ml}$; Invitrogen) dishes.

After dissection, NRP and GRP were cocultured for 5-10 d in the complete medium to generate a mixed population for grafting. Previous studies (Lepore et al., 2004; Lepore and Fischer, 2005) verified that these cultures contained only precursors and were devoid of multipotent stem cells and mature cell types. NRPs and GRPs were dissociated from culture flasks using $0.05 \%$ trypsin/EDTA, washed, and resuspended at a concentration of 100,000 cells $/ \mu \mathrm{l}$ (in basal media) for transplantation. Cells were placed on ice throughout the grafting session and grafted in an $\sim 1: 3$ ratio of NRP/GRP. After the completion of the grafting session, cell viability was assessed using the trypan blue assay. Viability was always found to be $>90 \%$. The composition of the NRP/GRP cultures, with respect to the absence of mature cells, was verified before grafting by staining for the mature neurons [neuronal-specific nuclear protein (NeuN)], astrocytes [glial fibrillary acidic protein (GFAP)], and oligodendrocytes [receptorinteracting protein (RIP)]. The purity of the culture with respect to lineage-restricted precursors was verified by staining for the immature neural marker nestin, and the ratio of NRP to GRP was determined by their corresponding markers, embryonic neural cell adhesion molecule and A2B5.

\section{Surgical procedure (Mitsui et al., 2005a)}

After anesthesia with intraperitoneal injection of XAK mixture containing xylazine $(10 \mathrm{mg} / \mathrm{kg})$, acepromazine maleate $(0.7 \mathrm{mg} / \mathrm{kg})$, and ketamine $(95 \mathrm{mg} / \mathrm{kg})$, a laminectomy was performed at T8/T9, and a contusion injury produced using the impact rod of the MASCIS device was dropped from a height of $25 \mathrm{~mm}$ (Gruner, 1992) and was allowed to rest on the spinal cord for $5 \mathrm{~s}$ This is a modification of the standard moderate contusion injury in which the impactor is immediately withdrawn, and it results in greater motor deficits than the standard injury (Mitsui et al., 2005a). The muscle and skin were closed in layers.

At $9 \mathrm{~d}$ after contusion, animals were reanesthetized with intraperitoneal injection of XAK mixture. Animals were placed in a spinal stereotaxic frame, and the spinal cord was reexposed. Using a $10 \mu \mathrm{l}$ Hamilton syringe with 30 gauge needle, cell culture medium (10 $\mu \mathrm{l})$ or mixed NRP and GRP (NRP/GRP, 25:75\%) were injected into the spinal cord. Five microliter deposits suspended in liquid collagen (Vitrogen; Cohesion, Palo Alto, CA) were injected at the injury center, and $2.5 \mu$ ldeposits were injected $3 \mathrm{~mm}$ rostral and caudal to injury center. Vitrogen was prepared according to the instructions of the manufacturer. Chilled $\left(4-6^{\circ} \mathrm{C}\right)$ Vitrogen was buffered at $\mathrm{pH} 7.4$ using $0.1 \mathrm{M} \mathrm{HCl}$ and $0.1 \mathrm{M} \mathrm{NaOH}$ and mixed with the appropriate cell number in their growth media (by volume, one-third Vitrogen plus two-thirds cells). Cells or medium were injected over 5 min under the control of a microsyringe pump controller (World Precision Instruments, Sarasota, FL), and the tip was slowly withdrawn. The syringe was thoroughly flushed with cell culture medium between each injection to prevent blockage. 
Within 10 min of the spinal cord injury, all rats received a bolus injection of methylprednisolone ( $30 \mathrm{mg} / \mathrm{kg}$; Pharmacia \& Upjohn, Kalamazoo, MI). Rats were placed on heating pads and closely observed until awake before returning to their home cage. Ampicillin (Bristol-Myers Squibb, Princeton, NJ) was injected twice daily for $7 \mathrm{~d}$ postoperatively as a prophylaxis for urinary tract infection. Bladders were manually expressed twice daily until the animals were killed, except during testing in the metabolic cages (described below).

\section{Immunosuppression with cyclosporine A}

All animals received subcutaneous administration of cyclosporin A (CsA) injection solution (Sandimmune; Novartis Pharmaceuticals, East Hanover, NJ) at a dose of $1 \mathrm{mg} / 100 \mathrm{~g}$ per $24 \mathrm{~h}$ beginning $3 \mathrm{~d}$ before the transplantation and continued for 2 weeks after transplantation. After this, oral CsA solution ( $50 \mu \mathrm{g} / \mathrm{ml}$; Neoral; Novartis Pharmaceuticals) was administered through the drinking water until the animals were killed.

\section{Urodynamic tests (Mitsui et al., 2005a)}

Micturition pattern. Rats were placed in a metabolic cage for $24 \mathrm{~h} \mathrm{(Nal-}$ gene metabolic cage; Nalge Nunc, Rochester, NY) to examine voiding behavior preoperatively and at weekly intervals after transplantation. The bladders of operated animals were expressed manually before the animals were placed in the metabolic cage. The urine voided during the next $24 \mathrm{~h}$ was collected on an electronic scale (FORT250; World Precision Instruments), connected to a microcomputer, for recording micturition frequency and volume (Mitsui et al., 2003, 2005a). Data were recorded and stored using data acquisition software (WINDAQ; DATAQ Instruments, Akron, $\mathrm{OH}$ ). The voided volume per micturition was compared among unoperated controls, OP-controls, and NRP/GRP groups.

Cystometry in awake rats. At 8 weeks after transplantation, rats were anesthetized under isoflurane inhalation, and a polyethylene catheter was implanted into the bladder. After $2 \%$ isoflurane inhalation, the bladder was exposed by a midline lower abdominal incision, and a polyethylene catheter (PE-60; Clay Adams, Parsippany, NJ) was implanted into the bladder through the dome, as described previously (Yoshiyama et al., 1999; Seki et al., 2002; Mitsui et al., 2003, 2005a). The bladder catheter was tunneled subcutaneously and exited through the skin on the back. A laminectomy was made above the level of iliosacral joint, and an intrathecal catheter was inserted through a slit made in the dura using the tip of a 30 gauge needle. The intrathecal catheter was passed rostrally to the L6-S1 level of the spinal cord, tunneled subcutaneously, and exited through the skin at the back of the rat. The location of the catheter tip was verified at the time of death.

After catheter implantation, rats were placed in a restraining cage (KN-326; Natsume, Tokyo, Japan) and allowed to recover for $1-2 \mathrm{~h}$. The bladder catheter was connected to a pressure transducer (BLPR; World Precision Instruments) and a microinjection pump (STC-523; Terumo, Tokyo, Japan). Room-temperature saline was infused at a rate of 0.1 $\mathrm{ml} / \mathrm{min}$, and intravesical pressure was recorded. Micturition cycles stabilized and became fairly regular after $\sim 30 \mathrm{~min}$ of saline infusion. Three micturition cycles were collected after stabilization. The averages of the maximal voiding pressure, postvoid residual urine, bladder capacity, and the frequency of DHR (the number of DHR per micturition episode) in these micturition cycles were compared among group. Micturition pressure provides a measure for DSD (Seki et al., 2002; Mitsui et al., 2003, 2005a). DHR was defined as rhythmic intravesical pressure increases $>5$ $\mathrm{mmHg}$ from baseline without a release of fluid from urethra (Yoshiyama et al., 1999; Mitsui et al., 2003, 2005a). Fluid voided from the urethral meatus was collected to determine the voided volume. The residual volume was then measured. Residual fluid was first withdrawn through the catheter, and then the bladder was expressed manually by applying pressure on the abdominal wall to collect the remaining intravesical contents. The bladder capacity was calculated as the voided volume plus residual volume. At the conclusion of these cystometric studies, we administered $10 \mu \mathrm{g}$ of Tamsulosin via the intrathecal catheter and reevaluated the cytometric parameters. Preliminary studies had shown that this dose, the highest that could be dissolved in $10 \mu \mathrm{l}$ of normal saline, was tolerated and improved urodynamic measures.
Tests of motor/sensorimotor function (Shumsky et al., 2003; Mitsui et al., 2005a)

Rats were habituated to the behavioral testing preoperatively and tested postoperatively at 2-3 d after injury, $7 \mathrm{~d}$ after injury, and every week after transplantation in open-field locomotion. Other tests were performed at $7 \mathrm{~d}$ after injury and 1, 2, 4, 6, and 8 weeks after transplantation. Performance was videotaped when appropriate, and mirrors were used for observation of contralateral limbs. All tests were scored by trained observers who had interrater reliability scores $>95 \%$. Observers were unaware of the group identity of the animals.

Thermal sensitivity. The latency of tail withdrawal in response to contact with heat stimulus was measured (adapted from Hargreaves et al., 1988; Yezierski et al., 1998; Eliav et al., 1999). Animals were habituated for 30 min in elevated Plexiglas cages (Ugo Basile, Comerio, Italy) below which a moveable radiant heat source $\left(25-29^{\circ} \mathrm{C}\right)$ could be applied. More intense stimuli are associated with vocalization and orienting responses; we chose a less aversive stimulus to diminish stress. Five trials were run, with a $15 \mathrm{~min}$ interval between each trial to prevent sensitization. The last four trials were averaged to provide the mean latency of withdrawal. This test has been shown to reveal a reduced latency to foot or tail withdrawal to thermal stimuli in rats with midthoracic hemisections (Hains et al., 2000; Coumans et al., 2001; Hains et al., 2002a,b, 2003b; Gwak et al., 2004) and cervical partial hemisections (Shumsky et al., 2003) and has been used as a model for neuropathic pain.

Grid test. Rats were placed on a plastic-coated mesh grid $(36 \times 38 \times 30$ $\mathrm{cm}$, length $\times$ width $\times$ height, with $3 \times 2 \mathrm{~cm}$ openings) and trained to walk across the grid. Paw placement on the grid bar for each hindlimb was assessed for $2 \mathrm{~min}$. Steps in which the paw gripped the grid bar and supported the animal's weight were counted as correct. The number of correct paw placements was expressed as a percentage of the total steps. The percentage of correct paw placements was calculated for each hindlimb and averaged. This test has been shown to be sensitive to damage of dorsal columns and corticospinal tract (CST) and to repair by grafts of fibroblasts secreting NT-3 (Grill et al., 1997)

\section{Hindlimb function}

Open-field locomotion. Rats were placed in an elliptical open field $(2.5 \times$ 3 feet diameter) and observed for $2 \mathrm{~min}$ by two trained observers. Hindlimb function was scored using the open-field locomotor rating [Basso, Beattie, and Bresnahan (BBB)] scale (Basso et al., 1995) from 0 (no observable movements) to 21 (normal locomotion). This test is sensitive to contusion injuries, showing deficits and partial recovery.

Treadmill. Stimulation by a moving treadmill may elicit reflex locomotion in SCI rats. Those rats that recovered to a BBB score of 8 were tested weekly on a motorized treadmill at $6.5 \mathrm{~m} / \mathrm{min}$ (Columbus Instruments, Columbus, $\mathrm{OH}$ ) and videotaped for $3 \mathrm{~min}$. Weight-supported steps were defined as those in which the hindquarters were raised above the treadmill belt. The number of weight-supported steps made by the hindlimbs was expressed as a percentage of its total steps as an index of locomotor function (Kim et al., 2001).

Exploratory rearing. When placed in a Plexiglas cylinder $(17.8 \times 35.5$ $\mathrm{cm}$ height), normal rats spontaneously rear and contact the walls with their forepaws, using the hindlimbs to support their weight. We examined rearing behavior in OP-controls and NRP/GRP rats at 8 weeks after transplantation. We evaluated rearing (rats that reared and extended the trunk with the hindlimbs flexed) and standing (animals reared and extended the trunk with the hindlimbs extended). Frequency of rears and stands was measured during the 3 min recorded observation period in the cylinder (Shumsky et al., 2003). Data are expressed as number of rears per minute and percentage of functional rears (number of rears + stands/total rears). This is a test of spontaneous hindlimb use.

\section{Tissue preparation (Lepore et al., 2004)}

Animals were anesthetized with intraperitoneal injections of sodium pentobarbital (100 mg/kg; Abbot Laboratories, North Chicago, IL) and killed via intracardiac perfusion with $200 \mathrm{ml}$ of $0.1 \mathrm{M}$ phosphate buffer (PB), pH 7.4, followed by $500 \mathrm{ml}$ of ice-cold $4 \%$ paraformaldehyde fixative in $\mathrm{PB}$. The spinal cord was then removed and postfixed for $24 \mathrm{~h}$ in the same fixative at $4^{\circ} \mathrm{C}$, followed by cryoprotection in phosphate-buffered 
$30 \%$ sucrose solution for 3-5 d. Tissues were serially blocked, embedded in OCT compound (Fisher Scientific, Houston, TX), and kept at $-80^{\circ} \mathrm{C}$ before being cut into $20 \mu \mathrm{m}$ sections at the lesion site or $30 \mu \mathrm{m}$ sections at the L6-S1 level on a cryostat. Longitudinal sections at the lesion site were mounted onto gelatin-coated slides, and coronal sections at the L6-S1 level were immersed in 0.1 M PBS, $\mathrm{pH}$ 7.6, for free-floating staining.

\section{Lesion size}

Lesion size and volume of spared host spinal cord were estimated from Nissl-myelin-stained sections. An $11 \mathrm{~mm}$ segment of thoracic spinal cord containing the lesion/transplant was sectioned longitudinally. Every 10th section was stained with Nissl-myelin, and the volumes of the lesion/transplant and spared tissue were calculated (Rosen and Harry, 1990). In each section, the total volume of the cord segment with the lesion epicenter in the middle was first determined. The volume of the cavity, damaged tissue, and graft were then measured. The volume of normal-appearing spinal tissue within the $11 \mathrm{~mm}$ spinal segment was determined by subtracting the cavity, damaged tissue, and graft volume from the volume of the entire segment.

\section{Alkaline phosphatase histochemistry}

Serial sections at the lesion site were analyzed using alkaline phosphatase histochemistry to determine the survival and migration of the grafted NRP and GRP cells. Sections were washed three times in PBS, heat treated at $60^{\circ} \mathrm{C}$ in PBS for $1 \mathrm{~h}$ to inactivate endogenous alkaline phosphatase, briefly washed in alkaline phosphatase buffer (in mm: 100 Tris, $100 \mathrm{NaCl}$, and $50 \mathrm{MgCl}_{2}, \mathrm{pH} 9.5$ ), and incubated at room temperature in the dark with alkaline phosphatase buffer containing $1.0 \mathrm{mg} / \mathrm{ml}$ nitrobluetetrazolium-chloride, $0.1 \mathrm{mg} / \mathrm{ml}$ 5-bromo-4-chlor-indolyl-phosphate, and $5 \mathrm{~mm}$ levamisole (Sigma) for $2 \mathrm{~h}$. Slides were coverslipped in aqueous mounting media and visualized using a light microscope.

\section{Phenotype analysis at the lesion site}

Sections were washed in PBS and blocked in $10 \%$ goat serum for $2 \mathrm{~h}$. The primary antibody was incubated with $2 \%$ goat serum in PBS containing $0.3 \%$ Triton X-100 at $4^{\circ} \mathrm{C}$ for $24 \mathrm{~h}$. Grafted cells were identified with a polyclonal antibody to human placental alkaline phosphatase (1:200; Accurate Chemicals, Westbury, NY). The following panel of primary antibodies was used to identify the phenotypic differentiation of grafted cells: microtubule-associated protein-2 (MAP2) (1:100; Chemicon, Temecula, CA) and NeuN (1:100; Chemicon) for neurons; GFAP (1:100; Chemicon) for astrocytes; RIP (1:1000; Chemicon) for oligodendrocytes; and nestin (1:1000; PharMingen, San Jose, CA) for immature neural cells. Axonal neurofilaments were identified using the monoclonal antibody RT-97 (1:500). Glycoproteins localized to synaptic vesicles were identified using an antibody against synaptophysin (1:500; Sigma). Species-specific fluorescence-conjugated secondary antibodies, goat anti-mouse or anti-rabbit conjugated to FITC or rhodamine (1:200; Jackson ImmunoResearch, West Grove, PA), were applied for $2 \mathrm{~h}$ onto slides at room temperature and then coverslipped with Vectashield (Vector Laboratories, Burlingame, CA) containing the nuclear counterstain 4',6'-diamidino-2-phenylindole. Fluorescently stained slides were stored at $4^{\circ} \mathrm{C}$.

\section{Projection patterns at L6-S1}

For immunocytochemical staining in the lumbosacral spinal cord, we used the avidin-biotin complex $(\mathrm{ABC})$ method. Sections were permeabilized with $10 \%$ goat serum in PBS for $2 \mathrm{~h}$, incubated with the appropriate primary antibody and $2 \%$ goat serum in PBS containing $0.3 \%$ Triton X-100 at $4^{\circ} \mathrm{C}$ for $24-72 \mathrm{~h}$, and finally reacted with a speciesspecific biotinylated secondary antibody and the $\mathrm{ABC}$ reagent (Vector Laboratories), each for $2 \mathrm{~h}$ at room temperature. Staining was visualized with Sigma fast DAB (Sigma). Tissue sections were mounted on gelatincoated slides, dehydrated in graded ethanol, cleaned in xylene, and coverslipped. All sections were examined with bright-field microscopy. The panel of primary antibodies used and their final dilutions were as follows: serotonin (5-HT) (1:50,000; ImmunoStar, Hudson, WI), CRF (1:4000; Chemicon), dopamine- $\beta$-hydroxylase $(\mathrm{D} \beta \mathrm{H})$ (1:1000; Protos Biotech, New York, NY), calcitonin gene-related peptide (CGRP) (1:6000; Penin- sula Laboratories, San Carlos, CA), vanilloid receptor type 1 (VR-1) (1:5000; Chemicon), growth-associated protein 43 (GAP-43) (1:50,000; Boehringer Mannheim, Mannheim, Germany), and synaptophysin (1: 3000; Sigma).

\section{Image analysis}

Images were captured using a Photometric Sensys KAF-1400 CCD camera (Roper Scientific, Trenton, NJ) attached to a Leica (Bannockburn, IL) DMRBE fluorescence microscope or on a Leica TCS SP2 laser confocal microscope. Images were analyzed using NIH Image, IP Lab (Scanalytics, Fairfax, VA), or Leica confocal software version 2.0. Adobe Photoshop 7.0 (Adobe Systems, San Jose, CA) was used to prepare figures.

For densitometry, five sections, chosen randomly, were viewed with a $10-20 \times$ objective, and the image was captured through a video camera attachment to the microscope. The image was converted using NIH Image into pixels on the computer monitor according to a grayscale that ranged in intensity from 0 (white) to 255 (black). The background level was determined from an area of ventral funiculus that did not exhibit immunoreactivity. This background value was used to set the threshold between labeled pixels and background pixels. The illumination intensity was held constant through the analysis of experimental operated and unoperated rats. A standard-sized rectangle was overlaid on the areas of interest and the labeled area within the rectangle was measured.

\section{Statistical analysis}

Cystometric data were analyzed using one-way ANOVA between groups. The effects of Tamsulosin were evaluated with Student's paired $t$ test (two tailed). Data from each behavioral test exhibited a normal distribution overall; therefore, statistical analysis was done using two-way ANOVA between group and time, with time taken as a repeated measure beginning at 1 week after transplantation. Post hoc analysis was performed using Fisher's post hoc test for the parametric data or the Mann-Whitney $U$ test for the nonparametric data (such as BBB scores). Immunocytochemical density data were analyzed using one-way ANOVA between groups, followed by Fisher's post hoc test when appropriate. Data are presented as group mean \pm SE. Significance levels were set to 0.05 for all comparisons.

\section{Results}

\section{Functional recovery}

Recovery of lower urinary tract function

Micturition pattern. After an initial period of areflexia, voided volume per micturition, measured in the metabolic cage, increased in both operated groups compared with preoperative or normal control values. This change is related to the increase in bladder capacity (Table 1), caused by bladder overdistention during the initial period of bladder areflexia.

ANOVA revealed a significant interaction between groups over time $\left(F_{(7,98)}=4.0 ; p<0.001\right)$. Voided volume per micturition increased in the NRP/GRP group by week 2 after transplantation, but OP-controls reached the same level only by week 4 (Fig. 1). Thus, NRP/GRP transplantation accelerated recovery of bladder contraction from the spinal shock phase and increased voiding efficiency at 2 and 3 weeks compared with OP-controls $(p<0.05)$.

When automatic voiding returned, voided volume per micturition remained greater in both operated groups compared with either baseline or normal controls. The total volume of voided urine and the water consumed did not differ between operated groups, although both were significantly greater (1.5-2 times normal values) than before spinal cord injury in normal rats (data not shown).

Cystometry. Cystometry was performed as a terminal experiment 8 weeks after transplantation. Representative charts from unoperated controls (Fig. 2A), OP-controls (Fig. 2B), and NRP/ GRP rats (Fig. $2 C$ ) are shown after intrathecal administration of saline $(0.9 \% \mathrm{NaCl} / 10 \mu \mathrm{l})$, for baseline cystometry, and of Tam- 
Table 1. Urodynamic parameters (cystometry) and bladder weight

\begin{tabular}{|c|c|c|c|c|c|c|}
\hline \multirow[b]{2}{*}{ Parameters } & \multicolumn{2}{|c|}{ Unoperated controls $(n=6)$} & \multicolumn{2}{|c|}{ OP-controls $(n=10)$} & \multicolumn{2}{|l|}{$\operatorname{NRP} / G R P(n=8)$} \\
\hline & Vehicle & Tamsulosin & Vehicle & Tamsulosin & Vehicle & Tamsulosin \\
\hline Micturition pressure (mmHg) & $19.5 \pm 1.0$ & $18.8 \pm 1.0$ & $33.4 \pm 1.2^{\dagger \dagger}$ & $25.5 \pm 1.2^{* *,+t}$ & $27.9 \pm 2.0^{\ddagger \neq, \S}$ & $22.9 \pm 1.9^{* *}$ \\
\hline Residual urine (ml) & $0.03 \pm 0.01$ & $0.02 \pm 0.01$ & $0.24 \pm 0.05^{\dagger}$ & $0.17 \pm 0.03^{t \dagger}$ & $0.14 \pm 0.08$ & $0.07 \pm 0.04$ \\
\hline Bladder capacity (ml) & $0.44 \pm 0.06$ & $0.45 \pm 0.01$ & $1.66 \pm 0.19^{\dagger \dagger}$ & $1.77 \pm 0.21^{t \dagger}$ & $1.53 \pm 0.17^{\neq \neq}$ & 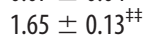 \\
\hline DHR (number of episodes/micturition) & 0 & 0 & $7.2 \pm 1.0^{\dagger \dagger}$ & $6.0 \pm 0.9^{*, t \dagger}$ & $3.4 \pm 0.9^{\ddagger \neq, \S}$ & $3.1 \pm 1.0^{\ddagger, \S}$ \\
\hline Bladder weight (mg) & $119.3 \pm 6.7$ & & $376.8 \pm 33.4^{\dagger \dagger}$ & & $289.6 \pm 19.6^{\ddagger \ddagger, \S}$ & \\
\hline
\end{tabular}

${ }^{\dagger} p<0.05,{ }^{\dagger \dagger} p<0.01$, unoperated versus OP-controls.

${ }^{\ddagger} p<0.05,{ }^{\neq \ddagger} p<0.01$, unoperated versus NRP/GRP.

${ }^{\S} p<0.05,0 P$-controls versus NRP/GRP.

${ }^{*} p<0.05,{ }^{* *} p<0.01$, vehicle versus Tamsulosin.

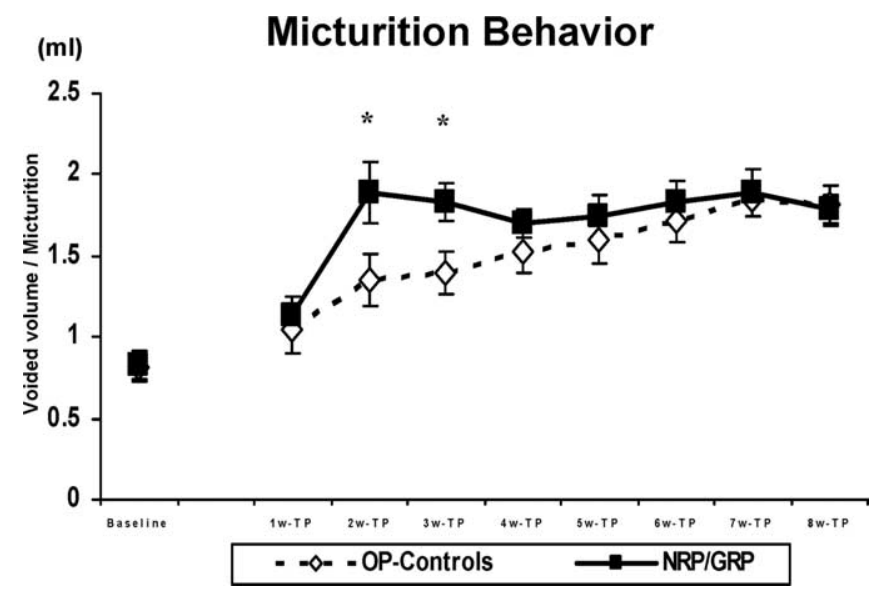

Figure 1. Micturition behavior in metabolic cages. The voided volume per micturition significantly increased in NRP/GRP recipients $(n=8) 2$ weeks after transplantation $\left({ }^{*} p<0.05\right)$ compared with OP-controls $(n=10)$. OP-controls reached the same level as NRP/GRP rats at week 4. Thus, NRP/GRP recipients showed an acceleration of recovery from areflexic bladder.

sulosin $(10 \mu \mathrm{g} / 10 \mu \mathrm{l})$. In unoperated control rats, saline infusion produced a gradual increase in intravesical pressure and then a single voiding contraction $\left(^{*}\right)$. When saline was infused into the bladder of the operated animals, rhythmic intravesical pressure waves $(\downarrow)$ appeared before voiding in both OP-controls and NRP/GRP groups. These rhythmic contractions were rarer $(p<$ $0.05)$ in NRP/GRP rats than in OP-controls. The pressure waves were not associated with release of fluid from the urethra and thus represented DHR. When micturition $\left(^{*}\right)$ occurred, micturition pressure was higher in OP-controls than in NRP/GRP rats, indicating amelioration of DSD in NRP/GRP recipients.

Urodynamic parameters in unoperated control, OP-control, and NRP/GRP rats are summarized in Table 1. ANOVA revealed significant differences among the three groups for all parameters. Post hoc analysis showed deficits between OP-controls and unoperated control rats for micturition pressure $(p<0.01)$, episodes of DHR $(p<0.01)$, bladder capacity $(p<0.01)$, and residual urine volume $(p<0.05)$. NRP/GRP recipients had improved micturition pressure $(p<0.05)$ and fewer episodes of DHR $(p<$ $0.05)$ compared with OP-controls. Although urodynamic parameters in the NRP/GRP group were improved, they remained significantly different from unoperated controls. The only exception was postvoid residual urine volume, which returned to values that did not differ from unoperated control rats.

After baseline cystometry, the $\alpha$-1A antagonist Tamsulosin $(10 \mu \mathrm{g} / 10 \mu \mathrm{l})$ was administered intrathecally. Because cystometry was performed as a terminal experiment, we studied only a single drug at a single dose to demonstrate the potential for a combined therapy. We chose Tamsulosin because $\alpha$-1-

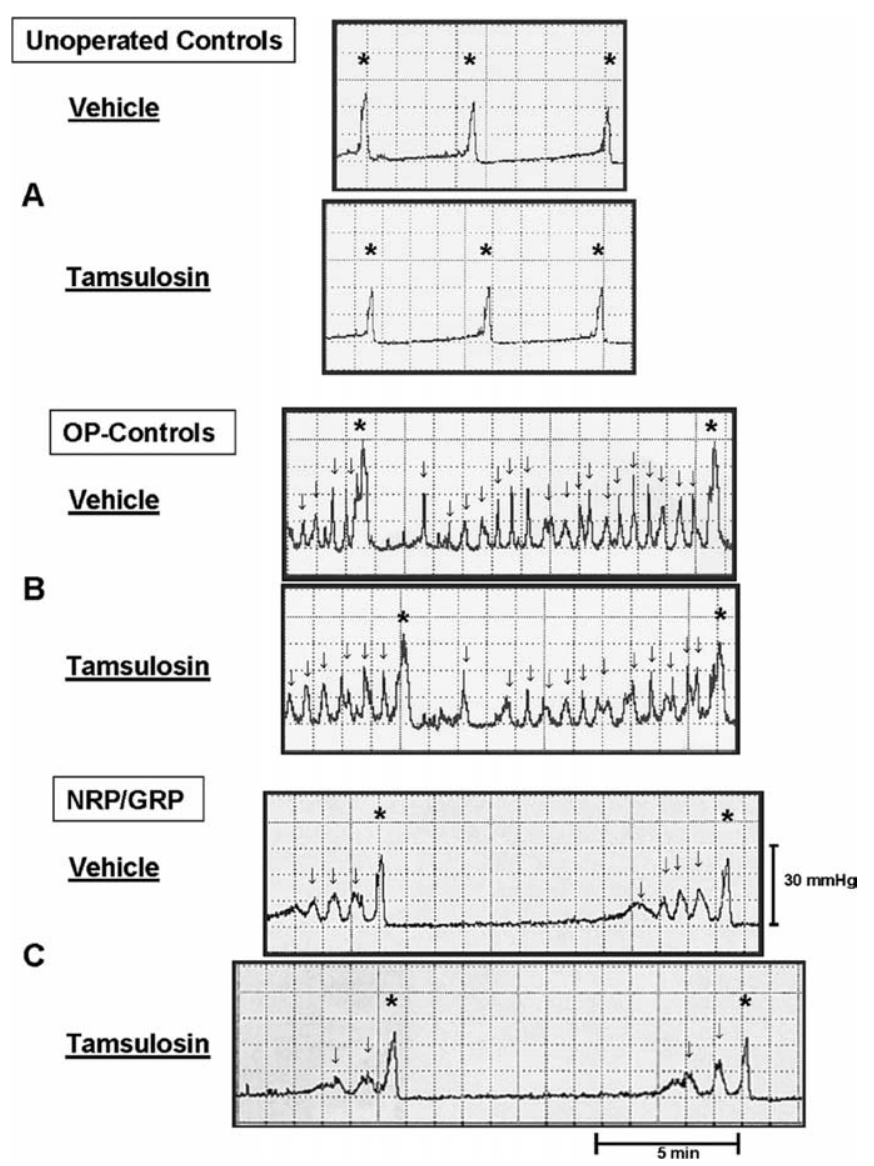

Figure 2. Representative cystometry charts of unoperated control, OP-control, and NRP/ GRP rats. $A$, Rhythmic contractions $(\downarrow)$ that do not result in voiding are not seen in unoperated control rats. Tamsulosin administration does not modify these patterns in normal rats. $\boldsymbol{B}$, When vehicle is infused into the bladder, rhythmic intravesical pressure waves $(\downarrow)$ appear before voiding $\left(^{*}\right)$. In OP-control rats, frequent rhythmic contractions occur, and these are only rarely associated with voiding $\left({ }^{*}\right)$. This indicates hyperactivity of the bladder (DHR). Micturition pressure $\left({ }^{*}\right)$ was higher compared with unoperated controls, indicating DSD. Tamsulosin administration decreases micturition pressure and the number of contractions that are not associated with voiding. C, NRP/GRP rats show lower micturition pressure $\left({ }^{*}\right)$ and few contractions that are not associated with voiding (DHR) ( $\downarrow$ ) after saline infusion compared with OP-controls. Tamsulosin administration slightly decreases micturition pressure and the number of reduced contractions that are not associated with voiding.

adrenergic receptors are implicated in bladder function and modified by SCI (Roudet et al., 1993; Danuser and Thor, 1995; Wada et al., 1996; Thor, 2003). In unoperated control rats, Tamsulosin had no significant effect on urodynamic parameters (Fig. $2 A$, Table 1). In both OP-control (Fig. $2 B$ ) and NRP/GRP (Fig. $2 C)$ rats, Tamsulosin administration improved urodynamic pa- 

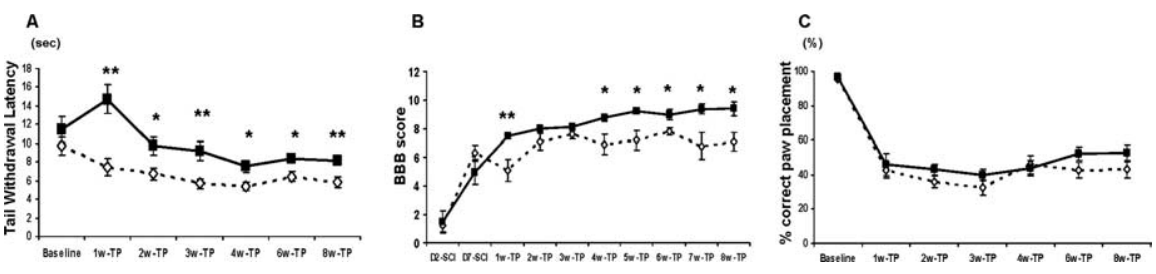

Figure 3. Amelioration of hypersensitivity to thermal stimuli and recovery of motor function $\left({ }^{*} p<0.05 ;{ }^{* *} p<0.01\right) . A$, Latency of withdrawal to thermal stimulus. The latency for tail withdrawal was decreased in both groups compared with baseline, but the NRP/GRP group showed significantly attenuated responses compared with OP-controls. $\boldsymbol{B}$, Hindlimb function. Hindlimb motor function was assessed using the open-field BBB scoring system. NRP/GRP transplanted rats showed improvement in BBB scores beginning at week (wk) 4 and maintained through week 8 compared with OP-controls. C, Grid test. Both operated groups showed sharply increased errors on the grid at 1 week after transplantation, with no functional improvement and no differences between the OP-control and NRP/GRP recipients. TP, Transplantation.

rameters so that they began to approach normal levels (Table 1). Tamsulosin produced significant improvement compared with vehicle in micturition pressure in both OP-controls $(p<0.01)$ and NRP/GRP $(p<0.01)$. Tamsulosin administration also significantly reduced episodes of DHR in OP-controls $(p<0.05)$ but did not further improve this measure in the NRP/GRP group. Tamsulosin did not improve bladder capacity or postvoid residual urine volume compared with vehicle, but the postvoid residual urine volumes in both operated groups were closer to normal values. ANOVA of these measures after Tamsulosin administration showed that NRP/GRP treated rats exhibited micturition pressures that were no longer different from unoperated controls, whereas pressures in OP-controls remained elevated $(p<$ 0.01 ). Thus, the combination of Tamsulosin administration with NRP/GRP transplants further improved lower urinary tract function in injured rats to levels approaching those in normal rats.

Bladder weight. Because DHR and functional bladder outlet resistance by DSD induce bladder hypertrophy by increasing the intravesical pressure, and thus the load on the bladder, we weighed the bladder after the animals were killed as a measure of hypertrophy (Table 1). ANOVA demonstrated that bladder weight was greater in both operated groups compared with unoperated controls $(p<0.01)$. Post hoc analysis showed that bladder weight was significantly less in the NRP/GRP group compared with OP-controls $(p<0.05)$, again indicating that NRP/ GRP transplants promote partial recovery of bladder function. The accelerated recovery of voiding could contribute to the reduction in bladder hypertrophy in NRP/GRP.

\section{Thermal sensitivity}

This test consists of applying a low-intensity heat $\left(\sim 27^{\circ} \mathrm{C}\right)$ stimulus to the tail, a stimulus described as an uncomfortably warm sensation in humans, and then measuring the latency to withdrawal. Unoperated control rats withdraw their tails with a latency of $12-15 \mathrm{~s}$. ANOVA revealed significant interactions between groups over time $\left(F_{(5,80)}=4.7 ; p<0.001\right)$, indicating that thermal hypersensitivity had developed at 1 week after transplantation in OP-controls but not until 2 weeks in the NRP/GRP group. Tail-withdrawal latencies in the NRP/GRP group remained significantly higher than OP-controls throughout the survival period $\left(F_{(1,16)}=24.0 ; p<0.001\right)$, although they did not fully recover to baseline levels. Thus, NRP/GRP transplants diminished the hypersensitivity that developed in the tail in OPcontrols (Fig. 3A).

\section{Recovery of spontaneous motor function}

Open-field locomotion (BBB test). We found that open-field locomotion was significantly better in the NRP/GRP group than in
OP-controls $\left(F_{(1,16)}=8.4 ; p<0.01\right)$. NRP/GRP recipients showed improvement in BBB scores by week 4 , achieving a score of $9.4 \pm 0.5$ by week 8 , which indicates weight support, whereas OP-control rats achieved a $\mathrm{BBB}$ score of $7.1 \pm 0.7$, without weight support (Fig. 3B). The somewhat lower BBB scores in the OPcontrol group compared with those normally seen (Basso et al., 1996) reflected the modified-moderate contusion lesion that we used. Because similar scores were recorded from OP-control animals with the same lesion, but that received no injection or injections of unmodified fibroblasts into the contusion site (Mitsui et al., 2005a,b), we believe the greater deficit was attributable to the difference in the contusion method rather than in the subsequent treatment. Nevertheless, the BBB score was improved in the NRP/GRP group compared with OP-controls and reached a level that allowed some weight-supported locomotion.

Treadmill. Rats that recovered some weight-supported stepping (BBB score $>8$ ) were evaluated on a treadmill. By 8 weeks after transplantation, 1 of the 10 OP-control rats achieved a BBB score of 9 , but none showed weight-supported stepping on the treadmill. In contrast, five of eight NRP/GRP rats demonstrated weight-supported stepping when stimulated by the treadmill, including one in which $55 \%$ of its steps were weight supported.

Rearing. When tested for exploratory rearing at 8 weeks after transplantation, only 3 of the $10 \mathrm{OP}$-control rats spontaneously used weight-supported rearing or a standing posture against the cylinder wall. Instead, they were more likely to explore the environment from a crouched position. In contrast, seven of eight rats in the NRP/GRP group exhibited functional rearing. They achieved an average of $59.2 \pm 11.7 \%$ functional rears compared with $8.5 \pm 4.6 \%$ in OP-controls $(p<0.05)$. An increase in rearing attempts was found in the NRP/GRP group compared with OP-controls ( $2.92 \pm 0.37$ vs $0.74 \pm 0.23$ rears $/ \mathrm{min} ; p<0.05)$, suggesting increased activity by the NRP/GRP recipients.

Grid test. Unoperated control rats locomote readily on a grid, placing the plantar surface of the paw centrally on the grid bar with few $(<5 \%)$ errors. Both groups of operated animals made more hindlimb foot faults, with no recovery and no difference between groups, although there was a tendency for the NRP/GRP group to display better paw placement at $6(p=0.14)$ and $8(p=$ 0.18 ) weeks after transplantation (Fig. $3 C$ ). Nevertheless, NRP/ GRP transplants into contused animals provided little improvement on this test, probably because they offered no protection to the dorsal columns or dorsal corticospinal tracts.

\section{Protection}

Lesion size

The modified-moderate contusion injury destroyed the dorsal spinal cord in the thoracic region, including the dorsal columns, the corticospinal tract, and the dorsolateral funiculus, damaged the dorsal horn, and impinged on the intermediolateral column. The ventral funiculi and the ventral portions of the lateral funiculi were spared. The Vitrogen matrix filled the injury cavity in OP-control animals and, in most cases, contained cells that had migrated from host tissue. From Nissl-myelin-stained sections, we calculated the spared/total spinal cord volume in NRP/GRP and OP-controls (Table 2). The volume of spared host spinal tissue was significantly greater in the NRP/GRP rats, indi- 
Table 2. NRP/GRP transplants diminish secondary injury after spinal cord injury

\begin{tabular}{lll}
\hline & OP-Controls & NRP/GRP \\
\hline Spared spinal cord volume $\left(\mathrm{mm}^{3}\right)$ & $10.7 \pm 1.3$ & $16.6 \pm 1.5^{*}$ \\
Spared spinal cord volume/total spinal cord volume (\%) & $57.0 \pm 1.7$ & $71.1 \pm 2.1^{* *}$ \\
\hline
\end{tabular}

${ }^{*} p<0.05,{ }^{* *} p<0.01,0 P$-controls versus NRP/GRP.

cating protection of host tissue and diminution of secondary injury by the NRP/GRP transplants. Cysts developed within the host (Fig. 4A), but fewer were seen in NRP/GRP recipients (Fig. $4 B$ ). In NRP/GRP recipients, the lesion cavity was filled with AP-positive NRP/GRP (Fig. 5A). $\mathrm{AP}^{+}$cells were also seen at sites of injection rostral and caudal to the injury epicenter. Some of the grafted cells migrated toward the lesion site to merge with those in the lesion cavity. Other $\mathrm{AP}^{+}$cells also had migrated considerable distances rostrally and caudally away from injection sites (Fig. 5A).

\section{NRP/GRP at the lesion site: neuronal phenotypes}

The grafted region was evaluated by staining for axonal neurofilaments with the RT-97 antibody. OP-controls (Fig. 4C) contained little RT-97 immunoreactivity adjacent to the lesion site or within the Vitrogen matrix in the lesion site. In contrast, the NRP/GRP group contained many axons within the graft (Figs. 4D, 5F). Thus, transplants of NRP/GRP formed a permissive environment for axon growth. Neuronal differentiation was assessed by colocalization of the AP transgene (green) with $\mathrm{NeuN}$ (red) (Fig. 5B, arrow, $\mathrm{NeuN}^{+} /$ $\mathrm{AP}^{+}$) or MAP2 (red) (Fig. 5C, arrow, $\left.\mathrm{MAP}^{+} / \mathrm{AP}^{+}\right)$. Graft-derived neurons were predominantly located close to the injection sites, in accordance with previous work demonstrating the limited migratory capacity of NRP (Han et al., 2002, 2004; Lepore et al., 2004). Synaptophysin immunoreactivity, a marker for synaptic vesicles (Wong et al., 1998), was abundantly distributed within the NRP/GRP transplant (Fig. 5F).

\section{Glial phenotypes}

Astrocytic differentiation was assessed by GFAP staining (Fig. 4E,F) and in NRP/ GRP recipients by colocalization of AP (green) and GFAP (red) (Fig. 5D, arrow, $\left.\mathrm{GFAP}^{+} / \mathrm{AP}^{+}\right)$, whereas identification of oligodendrocytic phenotypes was shown by RIP staining (Fig. 4G,H) and colocalization of AP (green) with RIP (red) (Fig. $5 E$, arrow, $\left.\mathrm{RIP}^{+} / \mathrm{AP}^{+}\right)$. In OP-controls, GFAP-immunoreactive (IR) cells were not present within the Vitrogen-filled lesion site but were densely distributed adjacent to the injury, in which they contributed to the glial scar (Fig. 4E). In contrast, in the NRP/GRP group, the distribution of astrocytes was more uniform within the graft, resembling that in normal tissue (Fig. $4 F$ ). In OP-controls, RIP-IR cells were absent from the Vitrogen graft and diminished in the host spinal cord adjacent to the glial scar (Fig. 4G). In contrast, in NRP/GRP recipients, RIP-IR cells were present within the transplant and in the host parenchyma (Fig. $4 H$ ), suggesting both protection of host oligodendrocytes and migration of GRP into the parenchyma. Graft-derived astrocytes and oligodendrocytes were present in the graft and near the site of engraftment. Both cell types were also found at considerable distances (up to $1 \mathrm{~cm}$ ) rostral and caudal to the injection sites in white matter. A small number of cells, including those that migrated the greatest distances, appeared to be immature, with bipolar (spindle) shapes and positive staining for nestin, a marker of undifferentiated cells (data not shown).

In summary, NRP/GRP survived, filled the lesion site, differentiated into neurons and glia, showed selective migration, and provided a local neuroprotective effect.

\section{Reorganization in lumbosacral spinal cord}

Primary afferent pathways

CGRP. CGRP-immunoreactivity in the DH and dorsal commissure (DCM) was denser in OP-controls than in NRP/GRP or unoperated controls (OP-controls vs NRP/GRP, $p<0.05$; OPcontrols vs unoperated controls, $p<0.05$ ), but there were no differences in CGRP projections to the DCM among the groups
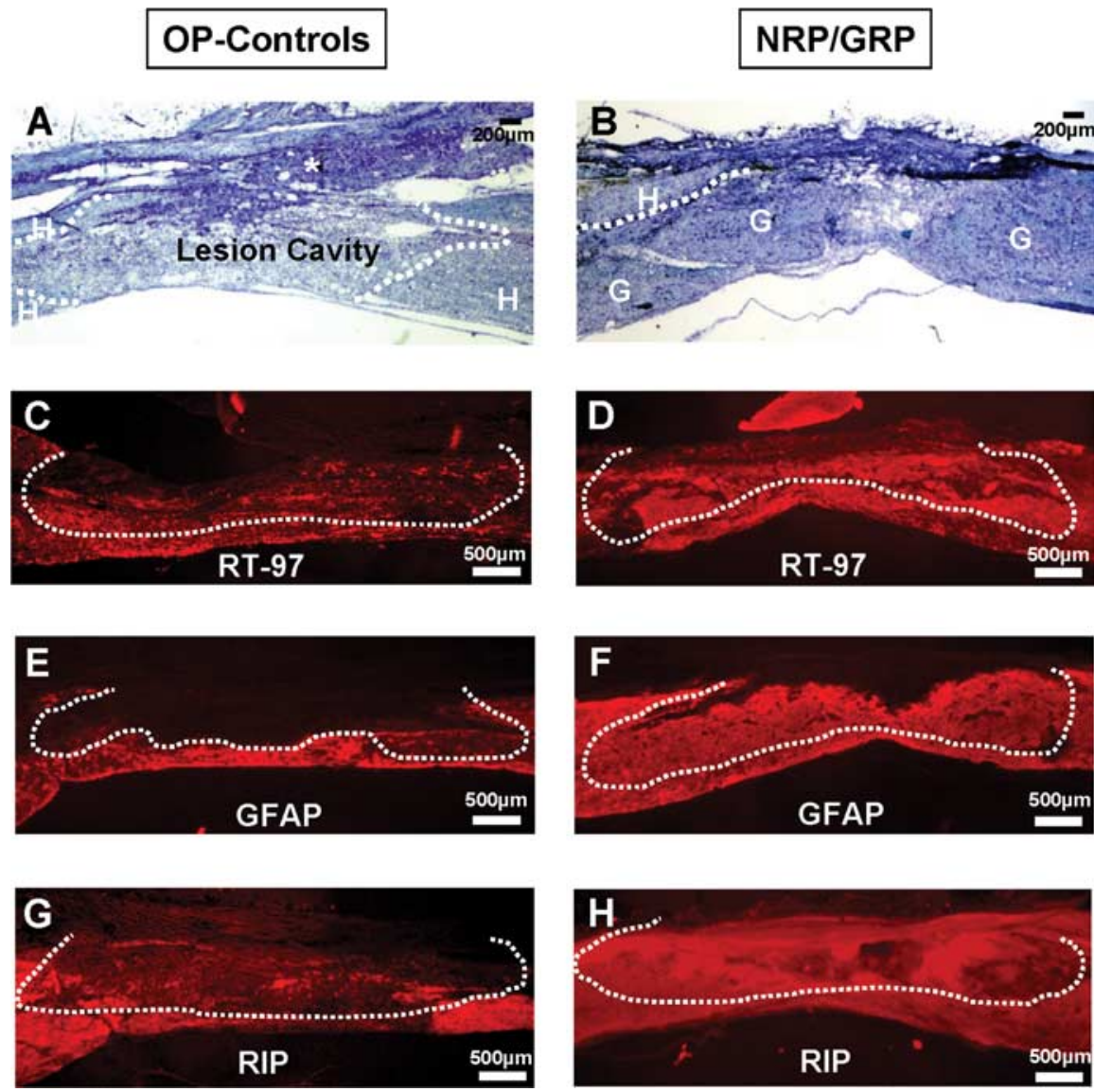

Figure 4. Nissl-myelin staining and immunocytochemistry at the lesion site. Dotted lines indicate lesion border. $\boldsymbol{A}$, Longitudinal section of spinal cord from OP-control rat. The injury site is filled with the Vitrogen matrix, into which some cells have migrated ( ${ }^{*}$, connective tissue; $H$, host). $\boldsymbol{B}$, Longitudinal section of spinal cord in Nissl-myelin staining shows survival of NRP/GRP transplanted into the injured spinal cord at 8 weeks after transplantation. The dotted line indicates graft-host interface. The cavity was primarily filled with transplanted cells, and few cysts were apparent (H, host; $G$, graft). C, Few RT-97 ${ }^{+}$axons were found within the Vitrogen matrix in OP-controls. D, In contrast, RT-97 axons were densely distributed within the graft in NRP/GRP. $\boldsymbol{E}$, In OP-controls, many GFAP ${ }^{+}$cells surrounded the lesion site, contributing to a glial scar. $\boldsymbol{F}$, In NRP/GRP recipients, many GFAP ${ }^{+}$ cells fill the transplant. $\mathbf{G}$, RIP $^{+}$cells were diminished adjacent to the lesion site in OP-controls, indicating demyelination. $\boldsymbol{H}$, $\mathrm{NRP} / \mathrm{GRP}$ recipients contained many $\mathrm{RIP}^{+}$cells within the graft. 
(1)
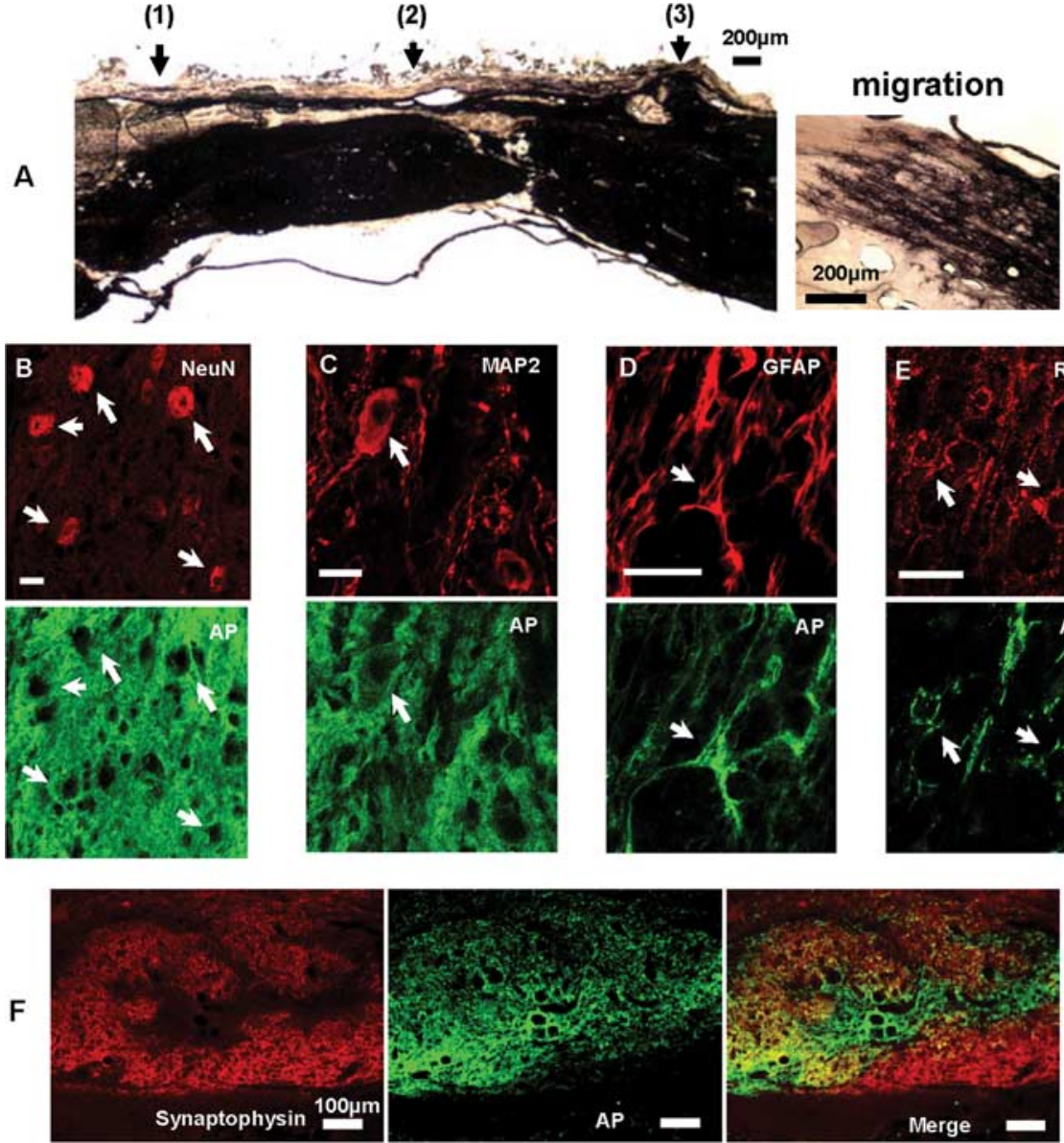

Figure 5. Confocal microscopy of immunocytochemical staining for phenotypes of transplanted cells, and axonal staining and synaptophysin immunoreactivity within the grafts. $\boldsymbol{A}$, Section of spinal cord adjacent to Figure 4 histochemically stained for AP to identify grafted cells. Injection sites were rostral to the lesion (1), at the lesion epicenter (2), and caudal to the lesion (3). The injection site is filled with $\mathrm{AP}^{+}$cells. $\mathrm{AP}^{+}$cells also migrated into the parenchyma and rostrally and caudally to the injection sites. Inset shows $\mathrm{AP}^{+}$cells at the rostral extents of migration into host tissue. $B, C$, Neuronal differentiation was assessed by colocalization of NeuN (red; $\boldsymbol{B}$ ) and MAP2 (red; $\boldsymbol{C}$ ) with the AP transgene (green) (NeuN ${ }^{+} / \mathrm{AP}^{+}$and MAP2 ${ }^{+} / \mathrm{AP}^{+}$cells, arrows). Scale bars, $20 \mu \mathrm{m}$. D, Astrocytic differentiation was assessed by colocalization of GFAP (red) with AP (green) (GFAP ${ }^{+} / \mathrm{AP}^{+}$cells, arrow). Scale bar, $20 \mu \mathrm{m}$. $\boldsymbol{E}$, 0ligodendrocytic phenotype was shown by colocalization of RIP (red) with AP (green) (RIP ${ }^{+} / \mathrm{AP}^{+}$ cells, arrow). Scale bar, $20 \mu \mathrm{m}$. F, Synaptophysin immunoreactivity. Abundant synaptophysin immunoreactivity was seen within the grafts, suggesting formation of presynaptic terminals and possible formation of synaptic connection within the graft and with the host.

(Figs. 6A, 7A). These results suggest increased sprouting of smallcaliber dorsal root axons to the DH in OP-control, compared with NRP/GRP, which resembled unoperated controls.

$V R-1$. Unmyelinated C-fiber afferents with high sensitivity to the neurotoxin capsaicin contribute to the bladder hyperreflexia and the increased sensitivity to noxious stimuli that occur after SCI. Capsaicin-binding sites have been identified as the membrane protein VR-1 (Catarina et al., 1997). In unoperated control rats, VR-1-positive fibers are thin and rather sparsely distributed in the superficial lamina (laminas I and II) of the DH and DCM. In OP-control rats, VR-1-IR fibers were coarser and were found in both the superficial laminas and in deeper laminas (III and IV). In rats with NRP/GRP transplants, the VR-1-positive fibers also appeared somewhat coarser than in unoperated control rats, and there was some invasion of VR-1-positive fibers into deeper laminas. There was, however, no difference in the density of VR-1 immunoreactivity between NRP/GRP and unoperated control rats in the DH (OP-controls vs NRP/GRP, $p<0.05$; OP-controls vs unoperated control, $p<0.05)$. The distribution of VR-1-
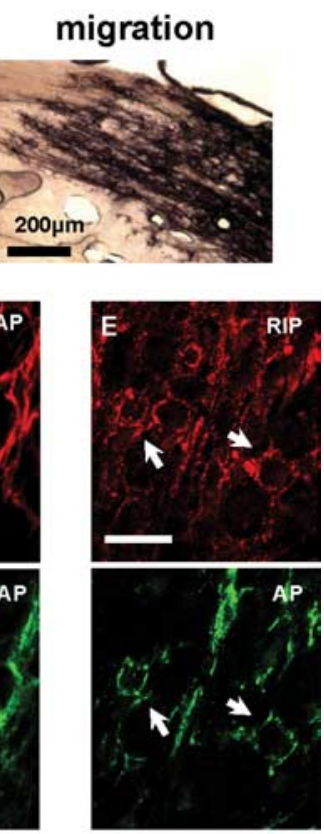

positive fibers in the DCM did not differ among the groups (Fig. 7B). Thus VR-1-IR axons sprouted in the DH of OP-controls, as described previously (de Groat et al., 1990, 1998; Zhou et al., 2002).

GAP-43. In the unoperated control spinal cord, GAP-43 was expressed in the DH, DCM, SPN, the lateral collateral pathway (LCP), and the CST (Figs. 6B, 7C), as shown previously (Vizzard, 1999). GAP-43 immunoreactivity was significantly increased in OP-controls in all regions except the CST compared with the unoperated controls $(p<0.05$ in the $\mathrm{DH}$, DCM, and LCP; $p<0.01$ in the SPN) (Figs. 6B, 7C), as reported previously (Vizzard, 1999). Increases in GAP-43 immunoreactivity in the NRP/GRP group were not seen in any of these regions, and there was no difference between unoperated control and NRP/GRP rats, except for the CST. GAP-43 was virtually absent from the CST of both operated groups compared with unoperated controls (OP-controls vs unoperated control, $p<$ 0.01 ; NRP/GRP vs unoperated control, $p<0.01$ ), consistent with the destruction of this tract by the thoracic contusion (Figs. 6B, 7C).

Synaptophysin. Because a thoracic contusion injury damages supraspinal projections to the $\mathrm{DH}$, a decreased synaptic density and thus a decreased density of synaptophysin immunoreactivity might be expected. Replacement of lost synapses by sprouting would, however, lead to a normal density of synaptophysin. We found no differences in density of synaptophysin immunoreactivity in $\mathrm{DH}$ among OP-control, NRP/GRP, and unoperated control rats (Figs. 6C, 7D). The similarity in density among the groups suggests that sprouting of afferent or descending pathways fibers restores synaptophysin density in the $\mathrm{DH}$ in both operated groups.

In summary, immunoreactivity for CGRP, VR-1, and GAP-43 in the $\mathrm{DH}$ increased in the OP-controls, but there were no differences in these measures between unoperated controls and NRP/ GRP, suggesting that the NRP/GRP transplants inhibited dorsal root sprouting.

\section{Descending modulatory pathways}

Serotonin-positive fibers. Several sites in the brainstem project serotonergic axons into the lumbosacral spinal cord. These pathways, particularly those projecting to the DL, have been implicated in the central control of bladder and urethra and recovery of bladder-external urethral sphincter coordination in SCI rats (Ding et al., 1995; Vizzard et al., 1995; Nadelhaft and Vera, 1996; Marson, 1997; Pikov and Wrathall, 2001). 5-HT-positive fibers in the DL were more densely distributed in NRP/GRP compared with OP-controls but less than in unoperated controls rats. The density of 5-HT fibers in NRP/GRP was thus intermediate between OP-controls and unoperated control rats and significantly 
different from both ( $p<0.01$ for all comparisons). In NRP/GRP recipients, but not unoperated controls or OP-controls, 5-HT fibers were identified in the lateral funiculus adjacent to the DL nucleus. Serotonergic projections to $\mathrm{DH}$ are associated with modulation of pain reception (Suzuki et al., 2002). Serotonergic fibers were observed in the DH in NRP/GRP with a density that was intermediate between unoperated control rats and OPcontrol rats and significantly different from both $(p<0.01$ for both comparisons). Thus, NRP/GRP may induce spouting, regeneration, or sparing of 5-HT projections to the DH and DL (Fig. 7E).

CRF-positive fibers. Barrington's nucleus contains numerous CRF-positive cells that project to the SPN (Valentino et al., 1996, 2000). The density of CRFpositive fibers in the SPN was intermediate between unoperated control and OPcontrol rats and different from both $(p<$ 0.01 for all comparisons). Interestingly, CRF fiber projections to the $\mathrm{DH}$ were very rare in the unoperated control rats, but many CRF-positive fibers were identified in NRP/GRP and some CRF-positive fibers were seen in OP-controls $(p<0.01$ for all comparisons) (Fig. $7 F$ ). CRF projections to DH and SPN were therefore increased in NRP/GRP recipients.

$D \beta H$-positive fibers. Noradrenergic axons from the brainstem project to the lumbosacral spinal cord innervating the lower urinary tract (Westlund et al., 1983; Vizzard et al., 1995; Marson, 1997), including the SPN. These inputs, particularly from the locus ceruleus, have been implicated in the supraspinal control of micturition. $\mathrm{D} \beta \mathrm{H}$-positive fibers were present in the DL (Fig. $8 A$ ), the SPN (Fig. $8 B$ ), and the DH (Fig. $8 C$ ) in unoperated control rats. The immunoreactivity was too sparse for accurate quantification, but the density of these axons in NRP/GRP appeared to be intermediate between unoperated control and OPcontrol rats.

In summary, the density of descending projections to the lumbosacral spinal cord was diminished in both groups of operated animals but to a lesser extent in the NRP/GRP group, suggesting sprouting or sparing of these pathways in NRP/GRP recipients.

\section{Discussion}

NRP/GRP cells transplanted into injured spinal cord survive, differentiate into neurons and glia, and offer protection to the host spinal cord. Bladder and hindlimb function improves, and hypersensitivity to thermal stimulus is decreased. In the lumbosacral cord, the NRP/GRP recipients showed increased density of descending modulatory pathways associated with bladder function, nociception, and motor control and decreased density of small-caliber dorsal root afferents to the dorsal horn.

\section{Lower urinary tract function}

Bladder dysfunction after SCI results from damage to descending pathways and alterations in primary afferent pathways. SCI produces an initial period of bladder areflexia, followed by the slow reemergence of involuntary reflex micturition and detrusor hy- perreactivity, both mediated by spinal reflex pathways. Coordinated function between bladder and urethral sphincter is disrupted after incomplete lesions, the degree of dyssynergia is related to the severity of the injury (Pikov and Wrathall, 2001), and there is no recovery from DSD after complete transection (our unpublished observations).

Some urodynamic parameters obtained through cystometry differ from spontaneous voiding and manual expression of the bladder (Keirstead et al., 2005) because of catheterization. We therefore compared volumes obtained through cystometry in operated rats. Voided volume per micturition was greater in both operated groups compared with baseline. Micturition thus remains inefficient because of DSD and DHR. This is attributable to alterations in bladder reflex pathways that have changed the set point for triggering micturition and to increased bladder outlet resistance produced by DSD and is correlated with the increase in the bladder capacity resulting from bladder overdistention during the areflexic period (Kruse et al., 1993).

Micturition pressures were, however, lower in the NRP/GRP groups, and there were fewer episodes of DHR compared with OP-controls, indicating amelioration of dyssynergia between bladder and urethral sphincter (Seki et al., 2002; Mitsui et al., 2003). We suggest that dyssynergia in SCI is associated with the loss of supraspinal projections into the lumbosacral spinal cord that normally modulate function and that the NRP/GRP cells transplanted into an incomplete injury effectively reduce the damage by reducing secondary injury to these modulatory systems. The fewer episodes of DHR in NRP/GRP rats suggest an attenuation of the hyperactive bladder reflexes that normally follow SCI, perhaps because sprouting from bladder afferents was diminished.

Noradrenergic pathways to the lumbosacral spinal cord par- 


\section{Area Fraction}

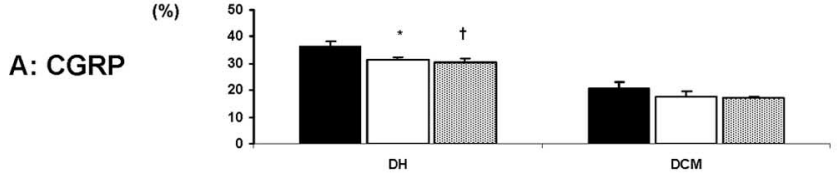

(\%)

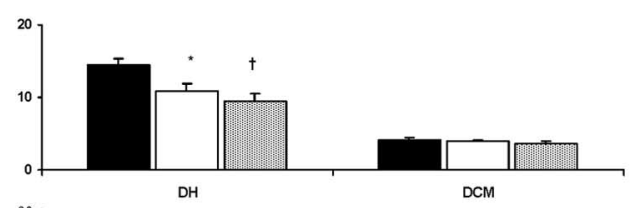

B: VR-1

(\%)

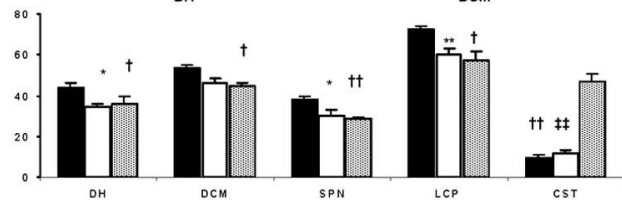

D: Synaptophysin

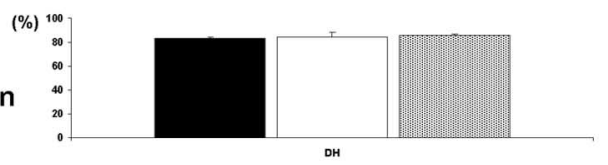

(\%)

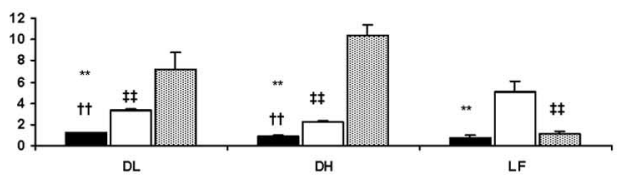

E: 5 -HT

(\%)

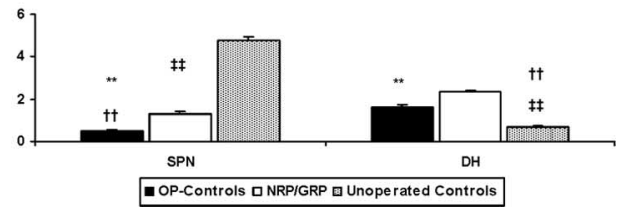

Figure 7. Quantification of immunoreactivity $\left({ }^{*} p<0.05,{ }^{* *} p<0.01\right.$ in $0 \mathrm{P}$-controls vs $\mathrm{NRP} / \mathrm{GRP} ; t p<0.05,+\dagger p<0.01$ in OP-controls vs unoperated-Controls; $\neq \neq p<0.01$ in NRP/ GRP vs unoperated controls). $\boldsymbol{A}$, GRP immunoreactivity in the DH was significantly denser in OP-controls than in NRP/GRP and unoperated controls, but there were no differences in DCM among groups. $\boldsymbol{B}, V R-1$ immunoreactivity was significantly denser in OP-controls than in NRP/ GRP and unoperated controls, but there were no differences in DCM among groups. C, GAP-43 immunoreactivity was significantly increased in the DH in OP-controls compared with NRP/GRP and unoperated controls. GAP-43 immunoreactivity in the CST was significantly less in both operated groups compared with unoperated controls. D, There were no differences in synaptophysin immunoreactivity among the groups. $\boldsymbol{E}, 5-\mathrm{HT}$ axons in the $\mathrm{DL}$ and $\mathrm{DH}$ were more densely distributed in NRP/GRP compared with OP-control rats, although less than in unoperated control rats, and serotonergic fibers were considerably more densely distributed in the lateral funiculus (LF) adjacent to the DL in the NRP/GRP group than in either unoperated control or OP-control groups. $\boldsymbol{F}$, CRF-positive fibers in the SPN of NRP/GRP rats were intermediate in density between unoperated control and OP-control groups. Many CRF-positive fibers were identified in the DH of NRP/GRP and some CRF fibers were observed in OP-controls compared with little or no CRF immunoreactivity in unoperated control rats.

ticipate in the control of micturition, and $\alpha$-1-adrenergic receptors in the spinal cord have a role in micturition (Durant et al., 1988; Ishizuka et al., 1996; Yoshiyama et al., 2000; Sugaya et al., 2002). Tamsulosin has been used clinically for treatment of voiding dysfunction and improvement in lower urinary tract function and symptoms of autonomic dysreflexia shown in randomized controlled trials in SCI patients (Abrams et al., 2003). Blockade of $\alpha$-1A-adrenergic receptors by Tamsulosin had no effect in normal rats but improved bladder function in OP-control rats and to a greater extent in NRP/GRP rats, presumably through its action on upregulated $\alpha-1$ receptors. The combination of pharmacotherapy with cellular transplants thus offers a rich potential in the search for treatments of bladder dysfunction.
L6-S1 spinal cord contains the SPN, preganglionic parasympathetic neurons that innervate the ganglia supplying the smooth muscle of the bladder wall (Nadelhaft and Booth, 1984), and the DL, which contains somatic motor neurons that innervate the external urethral sphincter and coordinate the activity of bladder and urethra. The increased density of descending projections to these nuclei in NRP/GRP may contribute to the amelioration of the dyssynergia between bladder and urethral sphincter that developed in the OP-controls. Bladder afferents project to the $\mathrm{DH}$, SPN, and DCM in the lumbosacral spinal cord (Jancso and Maggi, 1987; Steers et al., 1991). The density of CGRP-IR and VR-1-IR projections to the DH is increased after severe SCI (Krenz and Weaver, 1998; Krenz et al., 1999; Zhou et al., 2002; Hains et al., 2003a), and this has been implicated in the bladder dysfunction that develops after SCI. The NRP/GRP graft prevented the sprouting of dorsal roots, although the 5-HT, CRF, and $\mathrm{D} \beta \mathrm{H}$ axons were more densely distributed in the $\mathrm{DH}$. The descending projections may contribute to recovery of micturition reflexes by diminishing sprouting by $\mathrm{C}$-fibers and/or by providing greater descending control over sensory transmission in the DH (Ueyama et al., 1987; Athwal et al., 2001; Millan, 2002; Suzuki et al., 2002; Tsuruoka et al., 2004). We suggest that the sprouting of these primary afferents contributes to bladder dysfunction, specifically DHR, after SCI, but the more nearly normal immunoreactivity can account for the diminished DHR in the NRP/GRP rats.

\section{Recovery of sensorimotor function}

Withdrawal of limb or tail during noxious stimulation is an animal model for neuropathic pain (Hains et al., 2000; Lindsey et al., 2000; Coumans et al., 2001; Hains et al., 2002a,b, 2003b; Shumsky et al., 2003; Gwak et al., 2004), although it is recognized that hyperreflexia is difficult to differentiate from perception of pain in animals. When intense noxious stimulation is used in animals with incomplete lesions, vocalization is often evoked that provides behavioral support for the validity of this model. Using less intense stimuli, we showed that both groups of operated rats demonstrated the reduced latency that has been shown in other studies of SCI. (Hains et al., 2000, 2002a,b, 2003b; Lindsey et al., 2000; Coumans et al., 2001; Shumsky et al., 2003; Gwak et al., 2004). NRP/GRP rats, however, recovered near normal latencies, consistent with a decrease in lesion-related hypersensitivity or pain. The descending control of pain, like the descending control of autonomic function, is complex. It includes serotonergic and noradrenergic projections to spinal cord that modulate sensory processing in the DH (Athwal et al., 2001; Millan, 2002; Suzuki et al., 2002; Tsuruoka et al., 2004). The population of dorsal root afferents immunoreactive for CGRP and VR-1 include nociceptive axons, and the increase in density of these axons has been implicated in the increased sensitivity after SCI (Zhou et al., 2002; Hains et al., 2003a,b). Administration of antagonists to CGRP alleviates development of central pain after SCI (Bennett et al., 2000), and antagonists to VR-1 have been used in treatment of pain (Lopez-Rodriguez et al., 2003). Transplants of NRP/GRP into injured spinal cord, however, diminished sprouting by these primary afferent fibers in the lumbosacral DH and could account for the decreased hypersensitivity to a thermal stimulus applied to the tail in NRP/GRP compared with OP-control animals.

\section{Recovery of motor function}

$\mathrm{NRP} / \mathrm{GRP}$ rats also showed improvement in hindlimb function compared with OP-controls. The improvement in BBB was sufficient to permit some weight-supported stepping, which was 
further increased in response to stimulation by the movement of the treadmill. Weight support during rearing provided evidence of greater spontaneous functional use of hindlimb in the NRP/GRP group. The preservation of intact pathways in the lateral and ventral funiculi permits functional locomotion in the open field (Basso et al., 2002; Cao et al., 2005; Kloos et al., 2005) or on the treadmill and, for the NRP/GRP group, in functional rearing in the cylinder. This enhancement is consistent with greater sprouting or sparing of descending modulatory pathways that project to lumbar locomotor centers. The grid test assesses sensorimotor function, requiring integration of sensory and descending information to permit proper paw placement and weight support. Both operated groups developed marked deficits in the grid test with no recovery. The transplants of NRP/GRP cells were therefore not effective in overcoming these deficits produced by the contusion lesion, which destroyed the dorsal columns and dorsal corticospinal tract.

\section{Other lesions/other transplants}

In parallel studies (Mitsui et al., 2005a), we investigated urodynamic and behavioral recovery in rats that received transplants of fibroblasts genetically modified to secrete BDNF and NT-3 into a midthoracic contusion site. These animals showed patterns of recovery of bladder and motor function and modifications of lumbosacral circuitry that were quite similar to those described here for NRP/GRP recipients, although there was no reduction in sensitivity to thermal stimuli. We also shown that immortalized stem cell transplants placed in a thoracic compression lesion site restored some urodynamic functions but were less effective than the NRP/GRP transplants (Mitsui et al., 2003). Thus, we see a stratification of benefits of transplant types, with NRP/GRP transplants successful in restoring a wider range of function, including amelioration of hypersensitivity to a noxious stimulus. The mechanisms by which transplants act remain poorly understood but, in the case of stem cells or precursors, may include replacement of neurons that offers the possibility of developing novel relays, astrocytes that could provide axonal guidance, and oligodendroglia that could myelinate axons. The therapeutic value of neural stem cells and precursors may also include their potential to produce growth-promoting factors or mobilize endogenous stem cells (Rao and Mayer-Proschel, 2000). The extent to which NRP/GRP may contribute to these repair mechanisms has not yet been evaluated and may require development of methods of assessment of the functions of novel relays that form locally in thoracic spinal cord.

\section{Sprouting, sparing, and their roles in recovery}

We show that NRP/GRP grafts are associated with local neuroprotection, which may promote partial sparing of descending modulatory pathways that course through the lateral and ventral funiculi to the lumbosacral cord. Thus, the graft recipients have the potential for greater descending control over these spinal targets mediating control of autonomic function and nociception. Another mechanism is prevention of growth that contributes to dysfunction. Sprouting of the small-diameter dorsal root afferents that convey pain, temperature, and visceral information to the spinal cord has been implicated in autonomic dysfunction and in neuropathic pain, and we show that NRP/GRP transplants inhibit sprouting by these axons perhaps because sprouting by spared descending pathways is favored.

We have used immunocytochemical evidence of increased density at the light microscopic level to indicate sprouting. We showed a parallel between dorsal root-specific labeling and GAP-43 labeling in the DH, suggesting that primary afferent axons were in a growth state in OP-controls. The similarity of synaptophysin staining in the $\mathrm{DH}$ across groups would be consistent with a restoration toward normal levels of synaptic density by 
sprouting axons (Zhang et al., 1993). The different patterns of sprouting in the OP-control and NRP/GRP groups suggest that different pathways contribute to the restoration of synaptophysin staining in the DH: small-caliber dorsal root axons in the OPcontrol group and descending monoaminergic pathways in the NRP/GRP group. The increased density could also reflect an increase in transmitter within the spared terminals rather than an increase in number of terminals. The functional effects of greater axonal sparing or increased transmitter synthesis would also be expected to act to amplify the contribution of the pathway to the associated function.

\section{References}

Abrams P, Amarenco G, Bakke A, Buczynski A, Castro-Diaz D, Harrison S, Kramer G, Marsik R, Prajsner A, Stohrer M, Van Kerrebroeck P, Wyndaele JJ (2003) Tamsulosin: efficacy and safety in patients with neurogenic lower urinary tract dysfunction due to suprasacral spinal cord injury. J Urol 170:1242-1251.

Athwal BS, Berkley KJ, Hussain I, Brennan A, Craggs M, Sakakibara R, Frackowiak RS, Fowler CJ (2001) Brain responses to changes in bladder volume and urge to void in healthy men. Brain 124:369-377.

Basso DM, Beattie MS, Bresnahan JC (1995) A sensitive and reliable locomotor rating scale for open field testing in rats. J Neurotrauma 12:1-21.

Basso DM, Beattie MS, Bresnahan JC (1996) Graded histological and locomotor outcomes after spinal cord contusion using the NYU weight-drop device versus transection. Exp Neurol 139:244-256.

Basso DM, Beattie MS, Bresnahan JC (2002) Descending systems contributing to locomotor recovery after mild or moderate spinal cord injury in rats: experimental evidence and a review of literature. Restor Neurol Neurosci 20:189-218.

Bennett AD, Chastain KM, Hulsebosch CE (2000) Alleviation of mechani$\mathrm{cal}$ and thermal allodynia by CGRP $(8-37)$ in a rodent model of chronic central pain. Pain 86:163-175.

Cao Q, Zhang YP, Iannotti C, DeVries WH, Xu XM, Shields CB, Whittemore SR (2005) Functional and electrophysiological changes after graded traumatic spinal cord injury in adult rat. Exp Neurol 191 [Suppl 1]:S3-S16.

Catarina MJ, Schumacher MA, Tominaga M (1997) The capsaicin receptor: a heat-activated ion channel in the pain pathway. Science 389:816-824.

Chung K, Lee WT, Park MJ (1993) Spinal projections of pelvic visceral afferents of the rat: a calcitonin gene-related peptide (CGRP) immunohistochemical study. J Comp Neurol 337:63-69.

Coumans JV, Lin TT, Dai HN, MacArthur L, McAtee M, Nash C, Bregman BS (2001) Axonal regeneration and functional recovery after complete spinal cord transection in rats by delayed treatment with transplants and neurotrophins. J Neurosci 21:9334-9344.

Danuser H, Thor KB (1995) Inhibition of central sympathetic and somatic outflow to the lower urinary tract of the cat by the alpha 1 adrenergic receptor antagonist prazosin. J Urol 153:1308-1312.

de Groat WC, Kawatani M, Hisamitsu T, Cheng CL, Ma CP, Thor K, Steers W, Roppolo JR (1990) Mechanisms underlying the recovery of urinary bladder function following spinal cord injury. J Auton Nerv Syst [Suppl] 30:S71-S77.

de Groat WC, Araki I, Vizzard MA, Yoshiyama M, Yoshimura N, Sugaya K, Tai C, Roppolo JR (1998) Developmental and injury induced plasticity in the micturition reflex pathway. Behav Brain Res 92:127-140.

Ding YQ, Takada M, Tokuno H, Mizuno N (1995) Direct projections from the dorsolateral pontine tegmentum to pudendal motoneurons innervating the external urethral sphincter muscle in the rat. J Comp Neurol 357:318-330

Ding YQ, Zheng HX, Gong LW, Lu Y, Zhao H, Qin BZ (1997) Direct projections from the lumbosacral spinal cord to Barrington's nucleus in the rat: a special reference to micturition reflex. J Comp Neurol 389:149-160.

Durant PA, Lucas PC, Yaksh TL (1988) Micturition in the unanesthetized rat: spinal vs. peripheral pharmacology of the adrenergic system. J Pharmacol Exp Ther 245:426-435.

Eliav E, Herzberg U, Ruda MA, Bennett GJ (1999) Neuropathic pain from an experimental neuritis of the rat sciatic nerve. Pain 83:169-182.

Gibson SJ, Polak JM, Bloom SR, Sabate IM, Mulderry PM, Ghatei MA, McGregor GP, Morrison IM, Kelly JS, Evans RM, Rosenfeld MG (1984)
Calcitonin gene-related peptide immunoreactivity in the spinal cord of man and of eight other species. J Neurosci 4:3101-3111.

Grill R, Murai K, Blesch A, Gage FH, Tuszynski MH (1997) Cellular delivery of neurotrophin-3 promotes corticospinal axonal growth and partial functional recovery after spinal cord injury. J Neurosci 17:5560-5572.

Gruner JA (1992) A monitored contusion model of spinal cord injury in the rat. J Neurotrauma 9:123-128.

Gwak YS, Hains BC, Johnson KM, Hulsebosch CE (2004) Locomotor recovery and mechanical hyperalgesia following spinal cord injury depend on age at time of injury in rat. Neurosci Lett 362:232-235.

Hains BC, Chastain KM, Everhart AW, McAdoo DJ, Hulsebosch CE (2000) Transplants of adrenal medullary chromaffin cells reduce forelimb and hindlimb allodynia in a rodent model of chronic central pain after spinal cord hemisection injury. Exp Neurol 164:426-437.

Hains BC, Everhart AW, Fullwood SD, Hulsebosch CE (2002a) Changes in serotonin, serotonin transporter expression and serotonin denervation supersensitivity: involvement in chronic central pain after spinal hemisection in the rat. Exp Neurol 175:347-362.

Hains BC, Yucra JA, Eaton MJ, Hulsebosch CE (2002b) Intralesion transplantation of serotonergic precursors enhances locomotor recovery but has no effect on development of chronic central pain following hemisection injury in rats. Neurosci Lett 324:222-226.

Hains BC, Willis WD, Hulsebosch CE (2003a) Temporal plasticity of dorsal horn somatosensory neurons after acute and chronic spinal cord hemisection in rat. Brain Res 970:238-241.

Hains BC, Johnson KM, Eaton MJ, Willis WD, Hulsebosch CE (2003b) Serotonergic neural precursor cell grafts attenuate bilateral hyperexcitability of dorsal horn neurons after spinal hemisection in rat. Neuroscience 116:1097-1110.

Han SS, Kang DY, Mujtaba T, Rao MS, Fischer I (2002) Grafted lineagerestricted precursors differentiate exclusively into neurons in the adult spinal cord. Exp Neurol 177:360-375.

Han SS, Liu Y, Tyler-Polsz C, Rao MS, Fischer I (2004) Transplantation of glial-restricted precursor cells into the adult spinal cord: survival, glialspecific differentiation, and preferential migration in white matter. Glia 45:1-16.

Hargreaves K, Dubner R, Brown F, Flores C, Joris J (1988) A new and sensitive method for measuring thermal nociception in cutaneous hyperalgesia. Pain 32:77-88.

Hicken BL, Putzke JD, Richards JS (2001) Bladder management and quality of life after spinal cord injury. Am J Phys Med Rehabil 80:916-922.

Ishizuka O, Persson K, Mattiasson A, Naylor A, Wyllie M, Andersson K (1996) Micturition in conscious rats with and without bladder outlet obstruction: role of spinal alpha 1-adrenoceptors. Br J Pharmacol 117:962-966.

Jancso G, Maggi CA (1987) Distribution of capsaicin-sensitive urinary bladder afferents in the rat spinal cord. Brain Res 418:371-376.

Keirstead HS, Fedulov V, Cloutier F, Steward O, Duel BP (2005) A noninvasive ultrasonographic method to evaluate bladder function recovery in spinal cord injured rats. Exp Neurol 194:120-127.

Kim D, Adipudi V, Shibayama M, Giszter S, Tessler A, Murray M, Simansky KJ (1999) Direct agonists for serotonin receptors enhance locomotor function in rats that received neural transplants after neonatal spinal transection. J Neurosci 19:6213-6224.

Kim D, Schallert T, Liu Y, Browarak T, Nayeri N, Tessler A, Fischer, Murray M (2001) Transplantation of genetically modified fibroblasts expressing BDNF in adult rats with a subtotal hemisection improves specific motor and sensory functions. Neurorehabil Neural Repair 15:141-150.

Kloos AD, Fisher LC, Detloff MR, Hassenzahl DL, Basso DM (2005) Stepwise motor and all-or-none sensory recovery is associated with nonlinear sparing after incremental spinal cord injury in rats. Exp Neurol 191:251-265.

Krenz NR, Weaver LC (1998) Sprouting of primary afferent fibers after spinal cord transection in the rat. Neuroscience 85:443-458.

Krenz NR, Meakin SO, Krassioukov AV, Weaver LC (1999) Neutralizing intraspinal nerve growth factor blocks autonomic dysreflexia caused by spinal cord injury. J Neurosci 19:7405-7414.

Kruse MN, Belton AL, de Groat WC (1993) Changes in bladder and external urethral sphincter function after spinal cord injury in the rat. Am J Physiol 264:R1157-R1163.

Lepore AC, Fischer I (2005) Lineage-restricted neural precursors survive, 
migrate, and differentiate following transplantation into the injured adult spinal cord. Exp Neurol 194:230-242.

Lepore AC, Han SS, Tyler-Polsz CJ, Cai J, Rao MS, Fischer I (2004) Differential fate of multipotent and lineage-restricted neural precursors following transplantation into the adult CNS. Neuron Glia Biol 1:113-126.

Lindsey AE, LoVerso RL, Tovar CA, Hill CE, Beattie MS, Bresnahan JC (2000) An analysis of changes in sensory thresholds to mild tactile and cold stimuli after experimental spinal cord injury in the rat. Neurorehabil Neural Repair 14:287-300.

Lopez-Rodriguez ML, Viso A, Ortega-Gutierrez S (2003) VR1 receptor modulators as potential drugs for neuropathic pain. Mini Rev Med Chem 3:729-748.

Marson L (1997) Identification of central nervous system neurons that innervate the bladder body, bladder base, or external urethral sphincter of female rats: a transneuronal tracing study using pseudorabies virus. J Comp Neurol 389:584-602.

Millan MJ (2002) Descending control of pain. Prog Neurobiol 66:355-474.

Mitsui T, Kakizaki H, Tanaka H, Shibata T, Matsuoka I, Koyanagi T (2003) Immortalized neural stem cells transplanted into the injured spinal cord promote recovery of voiding function in the rat. J Urol 170:1421-1425.

Mitsui T, Fischer I, Shumsky JS, Murray M (2005a) Transplants of fibroblasts expressing BDNF and NT-3 promote recovery of bladder and hindlimb function following spinal contusion injury in rats. Exp Neurol 194:410-431.

Mitsui T, Ragupathi R, Shumsky JS, Amato N, Hanford K, Wieckowski K, Fischer I, Murray M (2005b) Acute NBQX administration and subacute NRP/GRP transplants improves bladder, sensory and motor function. Soc Neurosci Abstr 31:438.4.

Mujtaba T, Han SS, Fischer I, Sandgren EP, Rao MS (2002) Stable expression of the alkaline phosphatase marker gene by neural cells in culture and after transplantation into the CNS using cells derived from a transgenic rat. Exp Neurol 174:48-57.

Nadelhaft I, Booth AM (1984) The location and morphology of preganglionic neurons and the distribution of visceral afferents from the rat pelvic nerve: a horseradish peroxidase study. J Comp Neurol 226:238-245.

Nadelhaft I, Vera PL (1996) Neurons in the rat brain and spinal cord labeled after pseudorabies virus injected into the external urethral sphincter. J Comp Neurol 375:502-517.

O'Leary M, Erickson JR, Smith CP, McDermott C, Horton J, Chancellor MB (2003) Effect of controlled-release oxybutynin on neurogenic bladder function in spinal cord injury. J Spinal Cord Med 26:159-162.

Pannek J, Sommerfeld HJ, Botel U, Senge T (2000) Combined intravesical and oral oxybutynin chloride in adult patients with spinal cord injury. Urology 55:358-362.

Pikov V, Wrathall JR (2001) Coordination of the bladder detrusor and the external urethral sphincter in a rat model of spinal cord injury: effect of injury severity. J Neurosci 21:559-569.

Rao MS, Mayer-Proschel M (2000) Precursor cells for transplantation. Prog Brain Res 128:273-292.

Rosen GD, Harry JD (1990) Brain volume estimation from serial section measurements: a comparison of methodologies. J Neurosci Methods $35: 115-124$.

Roudet C, Savasta M, Feuerstein C (1993) Normal distribution of alpha-1adrenoceptors in the rat spinal cord and its modification after noradrenergic denervation: a quantitative autoradiographic study. J Neurosci Res 34:44-53.

Santajuliana D, Zukowska-Grojec Z, Osborn JW (1995) Contribution of alpha- and beta-adrenoceptors and neuropeptide- $Y$ to autonomic dysreflexia. Clin Auton Res 5:91-97.

Seki S, Sasaki K, Fraser MO, Igawa Y, Nishizawa O, Chancellor MB, de Groat WC, Yoshimura N (2002) Immunoneutralization of nerve growth factor in lumbosacral spinal cord reduces bladder hyperreflexia in spinal cord injured rats. J Urol 168:2269-2274.

Shumsky JS, Tobias CA, Tumolo M, Long WD, Giszter SF, Murray M (2003) Delayed transplantation of fibroblasts genetically modified to secrete BDNF and NT-3 into a spinal cord injury site is associated with limited recovery of function. Exp Neurol 184:114-130.
Steers WD, Ciambotti J, Etzel B, Erdman S, de Groat WC (1991) Alterations in afferent pathways from the urinary bladder of the rat in response to partial urethral obstruction. J Comp Neurol 310:401-410.

Sugaya K, Nishijima S, Miyazato M, Ashitomi K, Hatano T, Ogawa Y (2002) Effects of intrathecal injection of tamsulosin and naftopidil, alpha-1A and $-1 \mathrm{D}$ adrenergic receptor antagonists, on bladder activity in rats. Neurosci Lett 328:74-76.

Suzuki R, Morcuende S, Webber M, Hunt SP, Dickenson AH (2002) Superficial NK1-expressing neurons control spinal excitability through activation of descending pathways. Nat Neurosci 5:1319-1326.

Thor KB (2003) Serotonin and norepinephrine involvement in efferent pathways to the urethral rhabdosphincter: implications for treating stress urinary incontinence. Urology 62:3-9.

Tsuruoka M, Maeda M, Nagasawa I, Inoue T (2004) Spinal pathways mediating coeruleospinal antinociception in the rat. Neurosci Lett 362:236-239.

Ueyama T, Arakawa H, Mizuno N (1987) Central distribution of efferent and afferent components of the pudendal nerve in rat. Anat Embryol (Berl) 177:37-49.

Valentino RJ, Chen S, Zhu Y, Aston-Jones G (1996) Evidence for divergent projections to the brain noradrenergic system and the spinal parasympathetic system from Barrington's nucleus. Brain Res 732:1-15.

Valentino RJ, Kosboth M, Colflesh M, Miselis RR (2000) Transneuronal labeling from the rat distal colon: anatomic evidence for regulation of distal colon function by a pontine corticotropin-releasing factor system. J Comp Neurol 417:399-414.

Vizzard MA (1999) Alterations in growth-associated protein (GAP-43) expression in lower urinary tract pathways following chronic spinal cord injury. Somatosens Mot Res 16:369-381.

Vizzard MA, Erickson VL, Card JP, Roppolo JR, de Groat WC (1995) Transneuronal labeling of neurons in the adult rat brainstem and spinal cord after injection of pseudorabies virus into the urethra. J Comp Neurol 355:629-640.

Wada T, Otsu T, Hasegawa Y, Mizuchi A, Ono H (1996) Characterization of alpha 1-adrenoceptor subtypes in rat spinal cord. Eur J Pharmacol 312:263-266.

Weaver LC, Verghese P, Bruce JC, Fehlings MG, Krenz NR, Marsh DR (2001) Autonomic dysreflexia and primary afferent sprouting after clipcompression injury of the rat spinal cord. J Neurotrauma 18:1107-1119.

Westlund KN, Bowker RM, Ziegler MG, Coulter JD (1983) Noradrenergic projections to the spinal cord of the rat. Brain Res 263:15-31.

Widerstrom-Noga E, Cruz-Almeida Y, Krassioukov A (2004) Is there a relationship between chronic pain and autonomic dysreflexia in persons with cervical spinal cord injury? J Neurotrauma 21:195-204.

Wilson P, Kitchener PD (1996) Plasticity of cutaneous primary afferent projections to the spinal dorsal horn. Prog Neurobiol 48:105-129.

Wong TP, Campbel PM, Ribeiro-da-silva A, Cuello AC (1998) Synaptic numbers across cortical laminae and cognitive performance of the rat during aging. Neuroscience 84:403-412.

Yezierski RP, Liu S, Ruenes GL, Kajander KJ, Brewer KL (1998) Excitotoxic spinal cord injury: behavioral and morphological characteristics of a central pain model. Pain 75:141-155.

Yoshiyama M, Nezu FM, Yokoyama O, de Groat WC, Chancellor MB (1999) Changes in micturition after spinal cord injury in conscious rats. Urology 54:929-933.

Yoshiyama M, Yamamoto T, de Groat WC (2000) Role of spinal alpha(1)adrenergic mechanisms in the control of lower urinary tract in the rat. Brain Res 882:36-44.

Zhang B, Goldberger ME, Murray M (1993) Proliferation of SP- and 5HTcontaining terminals in lamina II of rat spinal cord following dorsal rhizotomy: quantitative EM-immunocytochemical studies. Exp Neurol 123:51-63.

Zhou Y, Wang Y, Abdelhady M, Mourad MS, Hassouna MM (2002) Change of vanilloid receptor 1 following neuromodulation in rats with spinal cord injury. J Surg Res 107:140-144. 